\title{
ENFERMEDAD MENTAL Y PRISIÓN: ANÁLISIS DE LA SITUACIÓN PENAL Y PENITENCIARIA DE LAS PERSONAS CON TRASTORNO MENTAL GRAVE (TMG)
}

\author{
Esther Hava García*
}

Resumen: La reforma psiquiátrica que acabó con los manicomios pretendía sustituir los planteamientos segregacionistas en el tratamiento de la enfermedad mental por un enfoque comunitario, pero las altas tasas de prevalencia de personas con TMG en prisiones indican que su segregación se produce ahora en el sistema carcelario. Las fuentes documentales, bibliográficas y jurisprudenciales consultadas parecen demostrar que el abordaje actual de esta problemática se caracteriza por el voluntarismo del personal de instituciones penitenciarias (que intenta paliar la escasez de recursos y la descoordinación entre administraciones implementando programas de tratamiento e intervención específicos), la indolencia de las comunidades autónomas (que se resisten a integrar la asistencia sanitaria

Recibido: agosto 2020. Aceptado: febrero 2021

* Catedrática de Derecho Penal. ORCID: 0000-0003-3505-2903

Facultad de Derecho de la Universidad de Cádiz. Dirección Avda. de la Universidad, 4. 11406. Jerez. Email: esther.hava@uca.es 
de estas personas en sus respectivos servicios de salud mental, lo que perjudica gravemente su atención penitenciaria y post-penitenciaria), y la severidad de los aplicadores de los órganos judiciales (que parecen excesivamente proclives al internamiento de estas personas, ya sean o no declaradas inimputables).

Palabras clave: Trastorno Mental Grave (TMG); régimen penitenciario; responsabilidad penal; inimputabilidad; medidas de seguridad.

\author{
MENTAL ILLNESS AND PRISON: \\ ANALYSIS OF THE PENAL AND PENITENTIARY \\ SITUATION OF INDIVIDUALS WITH SEVERE MENTAL \\ DISORDERS (SMD)
}

\begin{abstract}
The psychiatric reform that led to the closure of mental asylums aimed to replace their segregationist approach to mental illness with community-based alternatives. Yet the high prevalence of individuals suffering from SMD in prisons suggests that their segregation has now been shifted to the penitentiary system. An analysis of documentary, bibliographical and jurisprudential sources shows that the current framework is shaped by well-intentioned but constrained prison staff, who seek to remedy the lack of resources and the poor administrative coordination by implementing specific treatment and intervention programs; as well as by the unresponsiveness of the regional autonomous governments, who have resisted the integration of inmates with SMD within their broader mental health services, significantly limiting their access to treatment during and after their conviction; and by harsh a judicial system, that seems excessively inclined in favor of the internment of individuals with SMD, independently of their liability to stand trial. Keywords: Severe Mental Disorder (SMD); prison regime; criminal liability; insanity; security measure.
\end{abstract}




\section{Introducción}

Con carácter general, las personas con Trastorno Mental Grave $(T M G)^{1}$ no deberían estar en prisión. Parece una máxima aceptada de forma unánime tanto por las instancias supranacionales como por la comunidad científica, fruto de los avances experimentados por la Psiquiatría a lo largo de más de un siglo, que abandonó el método segregacionista en el tratamiento de la locura en favor de un enfoque más asistencial y, sobre todo, comunitario: el enfermo mental no tiene por qué ser más violento que un individuo "normal"; la persona con TMG que comete un hecho delictivo por regla general debe ser tratada de su enfermedad e integrada en el tejido social, no aislada detrás de las paredes de un centro de internamiento; la reclusión debe reservarse, como ultima ratio, para los casos más extremos de peligrosidad constatada.

1 A lo largo del presente artículo se emplea la expresión "Trastorno Mental Grave" (TMG) conforme a la definición que mayor consenso ha adquirido en la comunidad científica (NATIONAL INSTITUTE OF MENTAL HEALTH, Towards a Model for a Comprehensive Community-Based Mental Health System, Washington DC., NIMH, 1987). Dicha definición contempla tres dimensiones: a) diagnóstico clínico (trastornos psicóticos, excluyendo los orgánicos, incardinables en las categorías de la Clasificación Internacional de Enfermedades (CIE) de la Organización Mundial de la Salud de esquizofrenia -F20.x-, trastorno esquizotípico -F21-, trastornos delirantes -F22-, trastorno psicótico compartido F24-, trastornos esquizoafectivos -F25-, otros trastornos psicóticos no orgánicos -F28 y F29-, trastorno bipolar -F31.x-, episodio depresivo grave con síntomas psicóticos $-\mathrm{F} 32.3-$, trastorno depresivo mayor recurrente -F33- y trastorno obsesivo-compulsivo -F42); b) duración del trastorno (o cronicidad, que implica una evolución mínima de dos años, o bien un deterioro progresivo y marcado de la funcionalidad-abandono de roles sociales- en los últimos seis meses, o bien -como criterio alternativo- haber recibido tratamiento psiquiátrico más intenso que el ambulatorio más de una vez a lo largo de la vida, o apoyo residencial distinto a la hospitalización por tiempo suficiente para interrumpir significativamente la situación vital); y c) presencia de discapacidad (afectación de moderada a severa del funcionamiento personal, laboral, social y familiar ). Cfr. AAVV, Guía de Práctica Clínica de Intervenciones Psicosociales en el Trastorno Mental Grave, Ministerio de Sanidad y Política Social/ Ministerio de Ciencia e Innovación, 2009, pp. 31-32 
Al menos en teoría, nuestro ordenamiento punitivo cuenta con mecanismos, si no idóneos, al menos sí suficientes para minimizar la presencia de personas con TMG en el sistema penitenciario: a) si el enfermo mental cometió un hecho delictivo debido exclusivamente a su trastorno, deberá ser declarado no culpable (en tanto que inimputable), y solo en el caso de constatarse un pronóstico de peligrosidad futura habrá que imponerle una medida de seguridad (que no tiene que ser forzosamente privativa de libertad) adecuada para su tratamiento (arts. 95 y ss. CP); b) si la enfermedad mental influyó de manera significativa en su comportamiento delictivo (aunque no llegara a anular completamente su capacidad de culpabilidad) podrá aplicarse el sistema vicarial, que da prioridad al cumplimiento de una medida de seguridad (no necesariamente de internamiento) antes de proceder a la ejecución de la pena también impuesta (art. 104 CP), que además podrá ser suspendida si su cumplimiento pusiera en riesgo los efectos conseguidos con la medida aplicada; c) si el TMG se aprecia una vez pronunciada la sentencia firme e ingresado el declarado culpable en prisión, deberá suspenderse la ejecución de la pena e igualmente será posible decretar la imposición de una medida de seguridad (que tendrá que ser en este caso privativa de libertad, conforme a lo dispuesto en el art. $60 \mathrm{CP}$ ), con el fin de garantizar que el interno reciba la asistencia médica precisa ${ }^{2}$.

2 Un procedimiento similar (claramente mejorable) se prevé para cuando "el Juez advirtiese en el procesado indicios de enajenación mental", supuestos en los que deberá someterlo "inmediatamente a la observación de los Médicos forenses en el establecimiento en que estuviese preso, o en otro público si fuere más a propósito o estuviese en libertad" (arts. 381 LECR y 184.a) del Real Decreto 190/1996, de 9 de febrero, por el que se aprueba el Reglamento Penitenciario -RP). Por su parte, el art. 383 LECR establece que, "si la demencia sobreviniera después de cometido el delito, concluso que sea el sumario se mandará archivar la causa por el Tribunal competente hasta que el procesado recobre la salud, disponiéndose además respecto de éste lo que el Código Penal prescribe para los que ejecutan el hecho en estado de demencia". La virtualidad aplicativa de este último precepto ha sido drásticamente reducida por la jurisprudencia 
Cabe plantearse entonces el porqué, a pesar de dichas disposiciones legales, los dos hospitales psiquiátricos penitenciarios existentes en España se encuentran en una situación crónica de sobreocupación, y el porqué, según los datos oficiales, más del $4 \%$ de los reclusos internados en centros penitenciarios de cumplimiento ordinario padecen TMG; también cabe preguntarse en qué circunstancias se encuentran dichos reclusos, y si reciben un tratamiento adecuado a la enfermedad que padecen.

El presente artículo pretende aportar algo de luz a los interrogantes anteriores, analizando en primer lugar algunos de los hitos fundamentales de la reforma psiquiátrica posconstitucional, y cómo han influido en la situación actual de los enfermos mentales que se hallan ingresados en los establecimientos penitenciarios ordinarios y especiales; en segundo lugar, se describen algunas cuestiones clave que caracterizan a dicha situación, atendiendo a los datos disponibles sobre prevalencia de TMG en las prisiones españolas y a los principales programas específicos de intervención que se han abordado desde instituciones penitenciarias para tratar de mejorar (si no solucionar) las condiciones de este colectivo; en tercer lugar, y con el fin de esclarecer los criterios que manejan los aplicadores del Derecho en el enjuiciamiento penal

del Tribunal Supremo, dadas las exigencias que impone el principio de legalidad a la aplicación de medidas de seguridad -al respecto, véase por ejemplo la STS 844/2017, de 21 de diciembre. Mucho menos clara resulta la situación de "alegalidad" en la que se encuentran los sujetos con TMG declarados exentos de responsabilidad criminal en primera instancia y que se encuentran en prisión provisional durante la tramitación del recurso de casación, pues no existe disposición normativa que dé cobertura legal a una medida de reclusión cautelar en tales supuestos, y ello a pesar de que el Tribunal Constitucional ha expuesto en varias ocasiones al legislador la necesidad de poner fin a "este delicado vacío normativo" -la última de ellas, en la STC 84/2018, de 16 de julio. Sobre este último tema, véase LACAL CUENA, P., PEÑARANDA DEL RÍO, J. y SOLAR CALVO, P., “¿Debe un enfermo mental estar en prisión? Situación actual y cuestiones que plantea la STS 84/2018, de 16 de julio", Revista General de Derecho Penal, n³ 30, 2018, pp. 18 y ss. 
de personas con TMG, se presentan los resultados obtenidos tras el análisis de más de un centenar de resoluciones dictadas por el Tribunal Supremo en los últimos cinco años, en los que dicho órgano jurisdiccional se ha pronunciado sobre la mayor o menor relevancia del trastorno mental del acusado a la hora de dictaminar sobre su absolución o condena, y concretar las consecuencias penales de su comportamiento (que se traducen en regímenes penitenciarios diferentes). Finalmente, se exponen las principales conclusiones alcanzadas a lo largo del trabajo, las cuales, lamentablemente, no permiten augurar una mejora sustancial de la situación de los presos con TMG en un futuro próximo.

\section{La situación de los "dementes" en la época de Concepción Arenal: de los manicomios decimonónicos a la reforma psi- quiátrica postconstitucional}

La primera regulación positiva de una verdadera eximente basada en la enfermedad mental data del Código Penal de $1848^{3}$, que declaraba exentos de responsabilidad criminal al "loco" o "demente" y decretaba su reclusión cuando hubieren ejecutado un hecho que la ley calificara como delito grave, "en uno de los hospitales destinados á los enfermos de aquella clase, del cual no podrá salir sin previa autorizacion del mismo Tribunal". La idea de construir un manicomio propiamente penitenciario, que formalmente había surgido en

3 Ya con anterioridad, el artículo 26 del Código Penal de 1822 declaraba: "Tampoco se puede tener por delincuente ni culpable al que comete la acción (...) en estado de demencia ó delirio”. No obstante, las eximentes se recogen con una cierta sistemática por primera vez en el Código Penal de 1848 , cuyo artículo 8 declaraba exento de responsabilidad criminal a "1. "El loco ó demente, á no ser que haya obrado en un intervalo de razón". Esta fórmula legal "se modificaría en 1870, que declaró la irresponsabilidad del imbécil y del loco. La fórmula reducida («el enajenado») data de 1932, y habría que durar hasta 1995" (QUINTERO OLIVARES, G., Locos y culpables, Pamplona, Aranzadi, 1999, p. 59). 
$1886^{4}$, no se materializaría hasta bien entrado el siglo XX y una vez finalizada la guerra civil española. Así las cosas, al menos hasta $1920^{5}$ el destino de los locos sentenciados por la comisión de delitos (tanto de los declarados penalmente irresponsables por alienación mental, como de quienes enloquecían durante el cumplimiento de la pena de prisión) era por regla general el manicomio de su respectiva provincia (lugares donde tampoco eran bien recibidos, de forma que en muchas ocasiones eran devueltos a las cárceles ${ }^{6}$ ), salvo que la gravedad o duración de la pena impuesta justificara su ingreso en las dependencias habilitadas como manicomio en la Penitenciaría Hospital de El Puerto de Santa María?.

Las condiciones de hacinamiento, suciedad y abandono generalizado en la que se encontraba esta penitenciaría hospital ${ }^{8}$ eran igualmente constatables en los manicomios "civiles", lugares que RODRÍGUEZ LAFORA describía en

4 Con el Real Decreto de 13 de diciembre de 1886, que disponía la creación en Madrid de un Manicomio penal, proyecto que nunca se llevó a cabo. A partir de 1887 comienzan a trasladarse reclusos enajenados al Manicomio de Santa Isabel de Leganés (un viejo convento que fue habilitado como manicomio en 1851 y reinventado como establecimiento general de beneficencia dependiente del Ministerio de Gobernación en 1885), "ya que al fin y al cabo -se pensaba-alli estarían con los otros enajenados" (BARRIOS FLORES, L. F., "Un siglo de psiquiatría penitenciaria”, Revista Española de Sanidad Penitenciaria, Vol. 2, n 1, 2000, p. 25).

5 Cfr. CUEllo CALÓN, E., Penología. Las penas y las medidas de seguridad. Su ejecución, Madrid, Reus, 1920, p. 324.

6 BARRIOS FLORES, L. F., "Un siglo de psiquiatría penitenciaria”, cit., p. 26.

7 LÓPEZ LÓPEZ, A., "El enfermo mental y la legislación penitenciaria. Psiquiatría penitenciaria, perspectiva histórica y actual", en DELGADO BUENO, S. (dir.), Tratado de Medicina Legal y Ciencias Forenses V: Psiquiatría Legal y Forense, Barcelona, Bosch, 2013, p. 347.

8 Y que pronto obligaron a su desalojo, quedando durante algunos años como centro de reclusión de mujeres, hasta que en 1921 se reabrió ya como Prisión Central destinada al cumplimiento de penas de presidio mayor. Al respecto, véase MARTÍNEZ CORDERO, M., El penal de El Puerto de Santa María, ed. del autor, 2003, pp. 5 y ss. 
1916 como "refugios de desgraciados a quienes la sociedad quiere olvidar o ignorar". Muchos de estos establecimientos provinciales se asentaban en vetustos edificios de tres y cuatro siglos de antigüedad, insalubres y desmantelados, a los que calificaba como "lugares de atraso y de vergüenza nacional. Su organización entera se mantiene inmutable y de acuerdo con la época de creación. Ninguno de los avances del siglo XIX han impreso en ellos la más leve huella, y de esto son principales culpables los psiquiatras españoles que, ignorantes o abandonados, no han levantado nunca una voz de protesta que llegase hasta nuestros gobernantes" ${ }^{\text {. Según }}$ el mismo autor, en las instituciones oficiales para alienados de principios del siglo XX predominaba aún la "concepción política" de la locura ${ }^{10}$, en cuya virtud la sociedad sólo se preocupa de librarse del alienado, encarcelándole o recluyéndole: "Ya no cree que sea un poseído del diablo; pero tampoco le concede ningún derecho o consideración social"11. El discípulo de Ramón y Cajal ilustraba su artículo-denuncia con una serie de espeluznantes fotografías tomadas por él mismo en el transcurso de sus visitas a diferentes manicomios provinciales (los de Cádiz, Granada, Toledo, Madrid y Valencia), en las que pueden verse a enfermos, sucios y desnudos o solo cubiertos con un saco, yaciendo en sus celdas de piso de piedra y lecho de paja, o bien sujetados por recios

9 RODRÍGUEZ LAFORA, G., "Los manicomios españoles”, publicado originariamente en España. Semanario de la Vida Nacional, no 90 , 1916, pp. 8-10. Este artículo, así como las réplicas y contrarréplicas que suscitó, pueden verse en RODRÍGUEZ LAFORA, G.; PEREZ-VALDES, R. y BUSQUET, T.. "Los manicomios españoles", Revista de la Asociación Española de Neuropsiquiatría, Vol. 31, n 4, oct./dic. 2011, pp. 777-789.

10 Siguiendo en este punto la clasificación de las diferentes concepciones históricas de la locura (demonológica, política, fisiológica y psicológica) que realizara HART, B., The psychology of insanity, Cambridge University Press, 1912.

11 RODRÍGUEZ LAFORA, G.; PEREZ-VALDES, R. y BUSQUET, T.. "Los manicomios españoles", cit., p. 778. 
guardianes, que limitan aún más sus movimientos a pesar de las cadenas que llevan en los pies o en las manos, atadas a un cinturón metálico.

Esta es, sin duda, la misma cruda realidad a la que se refería CONCEPCIÓN ARENAL pocos años antes, cuando denunciaba la improcedencia de nombrar (como se había hecho) a un médico para elaborar una memoria sobre una hipotética Ley de Dementes, pues dicha norma no debería estar llamada a resolver problemas terapéuticos, sino jurídicos:

"Los derechos del demente, por lo mismo que son muy fáciles de atropellar, deben ser protegidos por la ley con particular esmero y estar rodeados de garantías especiales. Hay que fijar bien lo que constituye la demencia. Marcar sus varios grados. Graduar la pérdida de los derechos por la de la razón, que puede parcial o total. (...) La queja del criminal se escucha, la del loco no se atiende; ni su derecho es derecho, ni su justicia, justicia, una vez declarado ser sin razón, las que da no se aprecian, y se miran como una singularidad, como una rareza, como una reminiscencia de su perdido estado anterior, no como cosa respetable y atendible. Ya se comprende la gravedad de declarar a un ser racional fuera de la ley de la razón, y cuánto debe esforzarse el legislador para que sin derecho no se haga" ${ }^{\text {. }}$.

Se trata de una época, finales del siglo XIX y principios del XX, en la que los primeros avances de la psicopatología moderna (considerados los cimientos de la comprensión actual de los trastornos mentales) no habían llegado aún a España. No obstante, el panorama en otros países de nuestro entorno cultural tampoco era mucho mejor: también en ellos las instituciones mentales eran

12 ARENAL, C., "Ley de dementes", en Artículos sobre beneficencia y prisiones. Volumen III, Madrid, Librería de Victoriano Suárez, 1900. 
poco más que hospicios (cuando no meros presidios), varados en un criterio puramente de custodia que, frecuentemente, entraba en contradicción con la propia práctica clínica; esta situación, de sobra conocida ya entonces pero escasamente denunciada y discutida por pura conveniencia administrativa ${ }^{13}$, estaba propiciada por el temor que históricamente han suscitado los enajenados.

En efecto, como señala DOMÈNECH, "el enfermo mental ha sido tratado a menudo como una persona peligrosa, que inspiraba miedo y obligaba a la sociedad sana a defenderse de él. Un paso más allá estaba la necesidad que sentía mucha gente, por miedo unido a la ignorancia de librarse de un peligro potencial. Para ello se recurría a cualquier medio -el miedo lo justificaba- y no se reparaba en la situación en que se colocaba al alienado o demente. A menudo incluso los propios familiares allegados quedaban tranquilos cuando podían situarle lejos y se podían liberar de la preocupación que les causaba"14, enviándole a una institución (frecuentemente peor que la cárcel) en la que el enfermo mental ingresaba sin fecha prevista de salida, ni asistencia legal para su defensa. Dado que en ese momento la terapéutica aplicable a estos enfermos era aún prácticamente inexistente, la mayor preocupación era justificar su encierro, ayuno de tratamiento y caracterizado por aspectos puramente represivos y de defensa social ${ }^{15}$. El confinamiento del alienado se conseguía

13 PÉREZ FERNÁNDEZ, F. y PEÑARANDA ORTEGA, M., "El debate en torno a los manicomios entre los siglos XIX y XX: el caso de Nellie Bly", Revista de la Asociación Española de Neuropsiquiatría. 2011, Vol. 37, n' 131 , ene./jun. 2017, pp. 96-97.

14 DOMÈNECH, E., Introducción a la historia de la Psicopatología, Barcelona, PPU, 1991, p. 81.

15 "El aislamiento del loco en el manicomio, defendido por los alienistas contra viento y marea fue, sin duda, el fundamento de esta singularidad que conllevó la disociación entre la teoría médica y la práctica en el interior del asilo. Esta última estuvo más cercana al ejercicio del poder sobre el enfermo, a su reconducción como individuo para transformarle y aproximarle al ciudadano sensato, en definitiva a su normalización, 
mediante el cumplimiento de ciertos trámites burocráticos no excesivamente rigurosos: "De ahí que se enfocara la psiquiatría en parte como un problema legal, o médico legal si se quiere, y se la estudiara dentro del campo de esta disciplina. La posibilidad ulterior de valorar la responsabilidad de un enfermo que comete un delito dio algo más de contenido a esta vertiente médico legal de la psiquiatría. (...) Entre la adopción de las nuevas normas, la adaptación de la legislación y la mejora efectiva de los enfermos, transcurrieron docenas de años y aún todavía hoy no se les trata de forma humanitaria en todas partes"16.

Ya entrado el siglo XX, el alienismo español experimentó una importante transformación doctrinal que sentó las bases de la reforma asistencial emprendida durante la II República ${ }^{17}$, intentos modernizadores que no obstante pronto se vieron truncados con la guerra civil española. Surge entonces en el seno del régimen franquista una peculiar reinterpretación del concepto de "higiene mental" (concepción

que a la verdadera investigación científica y a la curación" (CAMPOS MARÍN, R. y HUERTAS GARCÍA-ALEJO, R., "Los lugares de la locura: reflexiones historiográficas en torno a los manicomios y su papel en la génesis y el desarrollo de la psiquiatría", Arbor. Ciencia, Pensamiento y Cultura, Vol. 184, nº 731, 2008, pp. 471-472).

16 DOMÈNECH, E., Introducción a la historia de la Psicopatología, cit., pp. 81-82.

17 En este momento, destaca CAMPOS MARÍN, "el problema de la criminalidad y sus relaciones con la locura abrió una importante vía de intervención de la psiquiatría fuera del manicomio como codificadora de comportamientos y como instrumento al servicio de la seguridad del Estado. Conceptos como la monomanía, el degeneracionismo y el del criminal nato lombrosiano, utilizados por los alienistas ante los tribunales con el firme propósito de demostrar la irresponsabilidad de los actos del encausado, así como la inexistencia del libre albedrío, determinaron la expansión de la psiquiatría más allá de los muros manicomiales. La antropología y la sociología criminal, que en buena medida bebían en la psiquiatría, introdujeron la necesidad de la profilaxis de la criminalidad y, por tanto, de actuación en el campo social" ("La psiquiatría en la ciudad. Higiene mental y asistencia extramanicomial en España en la década de 1920", Frenia, Vol. IV-1, 2004, pp. 101-102). 
que, aun con evidentes limitaciones, pretendía transformar la asistencia psiquiátrica ${ }^{18}$ ) como "higiene moral y racial", perspectiva que fue sostenida por una psiquiatría dura, fuertemente politizada y represiva, y que se mantendría hasta la década de los cincuenta. Los años posteriores del franquismo se caracterizaron por una aparente vuelta al enfoque científico (representado por la creación del Patronato Nacional de Asistencia Psiquiátrica ${ }^{10}$ ); lo que, sin embargo, no supuso en la práctica cambios relevantes, dado el desinterés institucional en implementar políticas destinadas a prevenir la enfermedad mental y modernizar la psiquiatría ${ }^{20}$.

Como en tantas otras cosas, hubo que esperar a la promulgación de la Constitución Española de 1978 para que se produjera una transformación real en el tratamiento y estatuto jurídico del enfermo mental. Es a partir de aquel momento cuando comienza a tomar forma en las políticas públicas el rechazo a los manicomios, explicitándose la necesidad urgente de reformarlos o clausurarlos, y propugnándose su reemplazo por nuevos diseños terapéuticos. Razones tanto técnicas (el fracaso constatado de las instituciones psiquiátricas

$18 \mathrm{Al}$ respecto, véase DUALDE BELTRÁN, F., "La profilaxis de la enfermedad mental en la psiquiatría franquista: esquizofrenia, eugenesia y consejo matrimonial”, Revista de la Asociación Española de Neuropsiquiatría, 24 (92), 2004, pp. 140-141.

19 Sobre dicho Patronato, RODRÍGUEZ NOGUERA, M.V, MOREIRA MARTÍNEZ, M. M., BUSTOS CARDONA, T. y SIMÓN LORDA, D., "PANAP (Patronato Nacional de Asistencia Psiquiátrica): un organismo público para la asistencia psiquiátrica durante la dictadura de Franco (1939-1975). El caso del Hospital Psiquiátrico de Tóen-OurenseGalicia-España", en PEREIRA, A. L. y RUI PITA, J. (eds.), V Jornadas Internacionais de História da Psiquiatría e Saúde Mental, Coimbra, Universidade de Coimbra, 2015, pp. 92 y ss.; NOVELLA, E. J., "Los límites de la tecnocracia: la modernización autoritaria de la asistencia psiquiátrica en la España del segundo franquismo", Dynamis, Vol. 39, $\mathrm{n}^{\circ} 1,2019$, pp. 77 y ss.

20 CAMPOS, R. y NOVELLA, E., , "La higiene mental durante el primer franquismo. De la higiene racial a la prevención de la enfermedad mental", Dynamis, 37 (1), 2017, pp. 66 y ss. 
de confinamiento) como éticas (la consagración de la dignidad como valor supremo del ordenamiento, el reconocimiento de los derechos fundamentales y otros pronunciamientos constitucionales ${ }^{21}$ ) avalaron la puesta en marcha en la década de los ochenta de un proceso de "desinstitucionalización"22, en cuya virtud el internamiento debía ser sustituido por un modelo comunitario, "potenciando los recursos asistenciales a nivel ambulatorio y los sistemas de hospitalización parcial y atención a domicilio", y desarrollando "los servicios de rehabilitación y reinserción social necesarios para una adecuada atención integral de los problemas del enfermo mental"23. De este modo, todas las estructuras y servicios públicos sanitarios (incluidos los correspondientes a la asistencia psiquiátrica) pasaron a estar integrados en el Sistema Nacional de Salud, correspondiendo a las distintas comunidades autónomas la organización de sus respectivos servicios ${ }^{24}$.

Con la reforma psiquiátrica postconstitucional, en definitiva, se emprendía la total equiparación del enfermo mental con el resto de pacientes: su hospitalización, cuando resultare necesaria, debía llevarse a cabo en las unidades

21 Entre ellos, lo dispuesto en el art. 49 CE: "Los poderes públicos realizarán una política de previsión, tratamiento, rehabilitación e integración de los disminuidos físicos, sensoriales y psíquicos a los que prestarán la atención especializada que requieran y los ampararán especialmente para el disfrute de los derechos que este Título otorga a todos los ciudadanos".

22 DESVIAT, M., "Los avatares de una ilusión: la reforma psiquiátrica en España", Cuadernos de Trabajo Social, Vol. 23, 2010, p. 254. REVELLES CARRASCO, M., "Personas reclusas con trastorno mental grave: el éxodo tras la reforma psiquiátrica en España", Revista de Historia de las Prisiones, $n^{\circ} 9$ (julio-diciembre 2019), pp. 113: "La desinstitucionalización, en Andalucía por ejemplo, devino en la reubicación forzosa 'no se sabe donde' de 2.800 residentes en 1985, al cerrarse los ochos hospitales psiquiátricos existentes".

23 Art. 20 de la Ley 14/1986, de 25 de abril, General de Sanidad.

24 BARRIOS FLORES, L. F., "Derecho y salud mental (logros conseguidos y retos pendientes en España). Informe SESPAS 2020", Gaceta Sanitaria, 2020, p. 2. 
psiquiátricas de los hospitales generales; en el orden civil, el internamiento involuntario pasaba a estar sujeto a control judicial (art. $211 \mathrm{CC}$, posteriormente derogado y sustituido por el art. 763 LEC); en el ámbito penitenciario, el principio asistencial provocaba el cierre de los antiguos (y terribles) establecimientos franquistas y su sustitución por los nuevos hospitales psiquiátricos penitenciarios ${ }^{25}$.

\section{La situación actual de los enfermos mentales en el sistema penitenciario: algunas cuestiones clave}

La reforma legal de la atención psiquiátrica emprendida hace ya más de tres décadas en España ha dado sus buenos frutos, aumentando el número y calidad de los recursos destinados a este tipo de asistencia sanitaria y mejorando la imagen social de las personas que padecen trastornos mentales (algo que, sin duda, resultó más evidente en aquellos lugares en los que la reforma trajo consigo el cierre de un manicomio y su sustitución por una red comunitaria) ${ }^{26}$. Sin embargo, nuestro país sigue adoleciendo de unos presupuestos para salud mental claramente insuficientes ${ }^{27}$, unos equipos de

25 En la década de los años noventa son clausurados el Departamento de Oligofrénicos de León, el Centro de Psicópatas de Huesca y el Sanatorio Psiquiátrico Penitenciario de Madrid (LÓPEZ LÓPEZ, A., "El enfermo mental y la legislación penitenciaria. Psiquiatría penitenciaria, perspectiva histórica y actual”, cit., p. 348-349).

26 DESVIAT, M., "Los avatares de una ilusión: la reforma psiquiátrica en España”, cit., pág. 256.

27 MUÑOZ ESCANDELL, I. (coord./red.), Informe sobre el estado de los derechos humanos en salud mental 2019, Confederación SALUD MENTAL ESPAÑA, Madrid, mayo de 2020, pp. 68-69: "mientras la media europea se encuentra en 18 profesionales de la Psicología Clínica por cada 100.000 habitantes, la salud mental continúa siendo la "hermana pobre" del sistema sanitario español, donde solo se cuenta con 4 profesionales por cada 100.000 habitantes. Esta situación repercute sobre las listas de espera y aboca a las personas, aquellas que se lo pueden permitir, al sistema privado. Aun así, los costes del sistema sanitario privado suponen un esfuerzo muy difícil de sobrellevar para muchas familias. 
tratamiento incompletos y una red comunitaria fragmentada, lo que provoca en muchos supuestos el uso excesivo de medidas de control y coerción en lugar de medidas terapéuticas ${ }^{28}$.

La escasez de recursos y la debilidad de los servicios comunitarios hacen que la atención psiquiátrica se dirija de forma casi exclusiva a los pacientes que visitan regularmente a los equipos de salud mental, dispositivos a los que con demasiada frecuencia no acuden voluntariamente las personas que padecen TMG, ya sea por carecer de conciencia de su enfermedad ya por pura opción personal, lo que les coloca con demasiada frecuencia en franca situación de abandono y ocasiona múltiples problemas, que son padecidos tanto por ellos mismos como por sus familias, vecinos y allegados, "no siendo infrecuente que terminen en las redes del sistema judicial-penal por hechos, generalmente no graves, que no son sino manifestación de su enfermedad" 29 .

El acceso a la justicia de estas personas suele producirse, además, en condiciones de inferioridad y/o vulnerabilidad

Esta realidad es aún peor en el caso de los niños y niñas con problemas de salud mental, ya que España es el único país de la Unión Europea, junto con Bulgaria, que no tiene la especialidad en Psiquiatría infantil y Juvenil. Esta carencia provoca peores pronósticos para la salud mental de este sector de la población, clave en lo que a prevención se refiere".

28 MUÑOZ ESCANDELL, I. (coord./red.), Informe sobre el estado de los derechos humanos en salud mental 2019, cit., p. 58.

29 ASOCIACIÓN ESPAÑOLA DE NEUROPSIQUIATRÍA (AEN), Por una atención integral a las personas con trastornos graves de salud mental basada en el respeto de sus derechos, Madrid, enero de 2009, p. 5. La propia Asociación señala el camino correcto para evitar dicha situación: "reforzar los servicios comunitarios de salud mental e introducir cambios sustanciales en su organización para afianzar ese carácter comunitario, con especial énfasis precisamente en la atención a esos pacientes que no solicitan y/o tienden a rechazar los tratamientos, garantizando intervención en crisis, atención domiciliaria y apoyo familiar, rehabilitación y continuidad de cuidados, y garantizando también una relación con las instituciones judiciales y las de tutela, e introducir esta dimensión asistencial en la formación de los profesionales y de los responsables de la planificación, gestión y evaluación de los servicios" (op. cit., p. 6). 
debidas a su trastorno mental: cuando el enfermo con TMG entra en contacto con las instancias policiales por protagonizar un incidente debido a una descompensación de su estado, existe una alta probabilidad de que el hecho se canalice en la vía penal a través de la redacción del correspondiente atestado y la instrucción de un procedimiento judicial, en el que fácilmente puede pasar desapercibida su enfermedad, dada la celeridad procesal que imponen los enjuiciamientos rápi$\operatorname{dos}^{30}$; los cuales, por lo demás, frecuentemente son resueltos con una sentencia de conformidad que es aceptada por el propio enfermo, disponiendo de escasa o nula información sobre sus derechos. En tales circunstancias, el destino de la persona con TMG que protagoniza un suceso de estas características parece predeterminado incluso cuando el enfermo mental no tiene antecedentes penales y el hecho cometido no es de los más graves (amenazas, lesiones leves, desobediencia o resistencia a la autoridad, etc.): la conformidad suele implicar la suspensión de la ejecución de la pena privativa de libertad, condicionada al cumplimiento de otras penas o medidas alternativas (arts. 83 y $84 \mathrm{CP}$ ), que con mucha frecuencia son quebrantadas, provocando en definitiva el ingreso en prisión $^{31}$.

30 REVIRIEGO PICÓN, F., "Derechos de los reclusos; el análisis desde la perspectiva de las personas con discapacidad", en CAMPOY CERVERA, I., Los derechos de los reclusos y la realidad de las cárceles españolas. Perspectivas sociales, políticas, jurídicas y filosóficas, colección "Debates del Instituto Bartolomé de las Casas", n² 27, Madrid, Dykinson, 2017, p. 144.

31 "Además, en el caso de delitos relacionados con la violencia familiar, se impone como pena accesoria a la persona afectada por el trastorno, una orden de alejamiento de su familiar que generalmente es quien ejerce el rol cuidador o cuidadora, tal como señala la Confederación Salud Mental España. El quebrantamiento de estas PMA favorecido por las dificultades de funcionamiento personal que caracterizan a las personas que padecen trastornos mentales graves, acaban provocando el ingreso en prisión" (MATEO SOLER, M., GÓMEZ DE TOJEIRO ROCE, J., ÁLVAREZ CRESPO, R., FERNÁNDEZ MODAMIO, M., BENGOECHEA IBACETA, J., FERNÁNDEZ IGLESIAS, P., GURRÍA FLORES, G., GIL SANZ, D., RÍOS MARTÍNEZ, J. y GAITE 
La situación de las personas con TMG que son correctamente diagnosticadas, (antes, durante o después del proceso penal), no es mucho mejor. Tras la reforma psiquiátrica y la consecuente desaparición de los manicomios, la tasa de camas en hospitales dedicadas de forma exclusiva a la atención de problemas mentales no ha cesado de caer, y tampoco se ha pensado en una alternativa a la institución penitenciaria para los enfermos que requieran este tipo de plazas en el marco de un proceso judicial, lo que ha traído como consecuencia la sobreocupación permanente de los hospitales psiquiátricos penitenciarios y la presencia de personas con TMG diagnosticado en las prisiones ordinarias, a la espera de que quede una plaza libre en el establecimiento psiquiátrico $^{32}$. Este escenario ya era denunciado por la Secretaría General de Instituciones Penitenciarias hace algunos años: "Los pacientes con enfermedades mentales crónicas, que en otro tiempo utilizaban centros sanitarios de larga estancia, ahora son transeúntes y foco de conflictos en un medio familiar y social cada vez con menor capacidad de soporte. En una frecuencia no despreciable acaban en la cárcel. Para algunos autores las cárceles se han convertido en los nuevos manicomios del siglo XXI"33.

A la escasez de plazas hospitalarias se añade la falta de recursos personales y materiales de que adolece el sistema penitenciario español para hacer frente a los problemas de salud mental que padecen buena parte de los internos. Según el Informe correspondiente a 2018 de la propia Secreta-

PINDADO, L., "Programa Puente Extendido. Salud mental en penas y medidas alternativas", Documentos Penitenciarios, $\mathrm{n}^{\circ}$ 18, 2018, p. 12).

32 Cfr. CASTEJÓN, M. A., PALLARÉS, J. y LÓPEZ, J. M., "Las personas con TMG en el ámbito penal y penitenciario. Situación actual y propuestas de intervención psicosocial“", Boletín de la Asociación Madrileña de Salud Mental, 2010, p. 14.

33 SECRETARÍA GENERAL DE INSTITUCIONES PENITENCIARIAS, Hospitales Psiquiátricos dependientes de la Administración Penitenciaria. Propuesta de Acción, 2011, p. 36. 
ría General de Instituciones Penitenciarias, durante ese año "se produjeron 19.679 ingresos en las camas de enfermería de los centros penitenciarios, de los cuales 8.423 fueron motivados por patología psiquiátrica $(42,8 \%)$ ", y a pesar de ello la especialidad de Psiquiatría no se presta en los centros de cumplimiento ordinario de algunas comunidades autónomas (como Andalucía y Navarra), de modo que en dichos centros la atención psiquiátrica debe canalizarse a través de los centros de salud mental comunitarios ${ }^{34}$; lo cual no debe resultar una tarea fácil, si se tiene en cuenta que sigue sin transferirse a las comunidades autónomas (con la sola excepción de Cataluña y País Vasco) los servicios sanitarios dependientes de Instituciones Penitenciarias, a pesar de que la disposición adicional sexta de la Ley 16/2003, de 28 de mayo, de cohesión y calidad del Sistema Nacional de Salud, daba un plazo de 18 meses desde su entrada en vigor para proceder a dicha integración ${ }^{35}$.

\subsection{Estudios sobre prevalencia de personas con TMG en las prisiones españolas}

La compleja problemática que plantea la presencia enfermos mentales en el sistema carcelario es conocida por el poder público desde hace tiempo. De hecho, el primer $E s-$ tudio sobre Salud Mental en el Medio Penitenciario, realizado en diciembre de 2006 en el seno de las propias Instituciones Penitenciarias, ya concluía que el $25,6 \%$ de la población reclusa (uno de cada cuatro internos) presentaba algún tipo de patología psiquiátrica, proporción que aumentaba de manera considerable si se incluía el abuso o dependencia de

34 SECRETARÍA GENERAL DE INSTITUCIONES PENITENCIARIAS, Informe General 2018, Madrid, Ministerio del Interior/Secretaría General Técnica, s/f, pp. 181 y 189.

35 Sobre los numerosos problemas que plantea el incumplimiento de dicha disposición adicional, véase RODRÍGUEZ YAGÜE, C., "El Derecho Penitenciario Humanitario", Anuario de Derecho Penal y Ciencias Penales, Vol. LXXII, 2019, pp. 471 y ss. 
drogas (una de cada dos personas ingresadas en prisión) ${ }^{36}$. La muestra estaba conformada por un millar de internos de todos los centros penitenciarios dependientes de la Dirección General de Instituciones Penitenciarias (exceptuando los hospitales psiquiátricos), y los datos se extrajeron de las historias clínicas de los individuos seleccionados, de modo que solo aportaban la prevalencia conocida y registrada en la correspondiente historia clínica. El uso de esta metodología constituye probablemente el principal factor que explica las divergencias constatadas con los resultados obtenidos en otros estudios similares realizados en países de nuestro entorno ${ }^{37}$, como Reino Unido (donde se concluyó que nueve de cada diez internos presentaban alguna alteración psíquica $)^{38}$.

Algunos años más tarde, en 2011, se publicó el estudio PRECA ("Prevalencia Cárceles"), el primero con un enfoque epidemiológico descriptivo (conforme a la clasificación DSM-IV ${ }^{39}$ ), que incluía una muestra de 707 penados entrevistados, todos ellos varones con edades comprendidas entre los 18 y los 75 años, e internados en los módulos ordinarios de cinco prisiones ubicadas en las comunidades de Cataluña, Madrid y Aragón ${ }^{40}$. La tasa de prevalencia de trastornos

36 SUBDIRECCIÓN GENERAL DE SANIDAD PENITENCIARIA, "Estudio sobre Salud Mental en el Medio Penitenciario. Diciembre 2006", incluido en MINISTERIO DEL INTERIOR, Estrategia Global de Actuación en Salud Mental, 2007, p. 12.

37 Dado "el bajo porcentaje de trastornos de personalidad recogidos en nuestras historias clínicas" (Ibídem).

38 SINGLETON, N., MELTZER, H., GATWARD, R. COID, J. y DEASY, D., Psychiatric morbidity among prisoners in England and $\mathrm{Wa}$ les, London, Stationery Office, 1998.

39 Esto es, la $4^{\text {a }}$ edición revisada del Diagnostic and Statistical Manual of Mental Disorders de la American Psychiatric Association, publicada en 1995. La última edición de esta obra es la siguiente: AMERICAN PSYCHIATRIC ASSOCIATION, Manual Diagnóstico y Estadístico de los Trastornos Mentales (DSM-5), $5^{\circ}$ ed., Madrid, Editorial Médica Panamericana, 2014.

40 Se excluyeron de la muestra del estudio PRECA a los internos preventivos, los ubicados en módulos psiquiátricos penitenciarios, los 
mentales a lo largo de la vida resultó ser significativamente más alta que la hallada en el estudio anterior: el $84,4 \%$ de los internos incluidos en la muestra presentaban algún tipo de trastorno mental. El trastorno por uso de sustancias fue el más frecuentemente hallado $(76,2 \%)$, seguido del trastorno de ansiedad (45,3\%), el trastorno afectivo (41\%) y el trastorno psicótico $(10,7 \%)$, que se presentaba asimismo como trastorno comórbido (junto con el uso de sustancias tóxicas o estupefacientes) en un $13,7 \%$ de los casos. De hecho, solo 57 reclusos (un 8\% del total) presentaban algún trastorno mental sin historial de consumo de drogas. Los datos anteriores demostraban, además, que la prevalencia de enfermedad mental entre la población reclusa era aproximadamente cinco veces más alta que en la población general española ${ }^{41}$.

El ámbito abarcado por otras investigaciones ha sido más circunscrito, pero presentan la ventaja de estar enfocados de forma específica en el análisis de los trastornos mentales más graves. Así, en 2012 se publicaba un estudio sobre prevalencia de TMG en los tres centros penitenciarios de El Puerto de Santa María (Cádiz). La muestra estaba compuesta por 128 internos reclutados a partir de la hoja de interconsulta de psiquiatría, desde junio de 2009 a mayo de 2010, y los diagnósticos se establecieron siguiendo los criterios del CIE- $10^{42}$. La prevalencia de TMG obtenida fue del 46,09\%:

pendientes de traslado o de puesta en libertad en los próximos seis meses y aquellos que poseían un bajo dominio de la lengua española. VICENS, E., TORT, V., DUEÑAS, R. M., MURO, A., PÉREZ-ARNAU, F., ARROYO J. M., ACÍN, E., DE VICENTE, A., GUERRERO, R., LLUCH, J., PLANELLA, R. y SARDA, P., "The prevalence of mental disorders in Spanish prisons", Criminal Behaviour and Mental Health, $\mathrm{n}^{\circ} 21,2011$, p. 323.

41 VICENS, E., TORT, V., DUEÑAS, R. M., MURO, A., PÉREZ-ARNAU, F., ARROYO J. M., ACÍN, E., DE VICENTE, A., GUERRERO, R., LLUCH, J., PLANELlA, R. y SARDA, P., "The prevalence of mental disorders in Spanish prisons", cit., pp. 324-328.

42 Es decir, la $10^{\mathrm{a}}$ edición de la Clasificación Internacional de Enfermedades publicada por la Organización Mundial de la Salud, en vigor desde 
59 internos, de los cuales 33 (esto es, un 55,93\% de los TMG y un $25,78 \%$ de la muestra total) padecían trastornos del espectro esquizofrénico clasificados en el grupo F20-29 del CIE-10 (esquizofrenia, trastorno esquizotípico y trastorno de ideas delirantes). 99 internos (esto es, un 77,34\%) consumían algún tipo de sustancias en el momento del estudio, y el 60,94\% (78 pacientes) presentaba antecedentes personales psiquiátricos ${ }^{43}$.

En 2017 se publicaron los resultados de una investigación que replicaba la metodología seguida en el estudio PRE$\mathrm{CA}$ en dos centros de la Comunidad de Castilla-La Mancha (Ocaña I y Ocaña II) y uno de la Comunidad de Madrid (Madrid VI), si bien partiendo de una muestra notoriamente más reducida (184 penados) ${ }^{44}$. Los resultados obtenidos en esta

1990. El grupo F20-29 del CIE-10 incluye las esquizofrenias, el trastorno esquizotípico, el trastorno delirante y otros trastornos psicóticos no relacionados con el estado de ánimo.

43 MARÍN-BASALlOTE, N. y NAVARRO-REPISO, C., "Estudio de la prevalencia de trastorno mental grave (TMG) en los centros penitenciarios de Puerto I, II y III del Puerto de Santa María (Cádiz): nuevas estrategias en la asistencia psiquiátrica en las prisiones", Revista Española de Sanidad Penitenciaria, Vol. 14, n ${ }^{\circ}$ 3, 2012, pp. 82-83. Resulta igualmente interesante el estudio realizado por CEREZO y DÍAZ sobre los expedientes de los 51 internos que se encontraban cumpliendo medidas de seguridad de internamiento en el Centro penitenciario de Alhaurín de la Torre entre octubre de 2007 y agosto de 2014; entre las patologías halladas, las del espectro de la esquizofrenia y otros trastornos psicóticos suponían un 33,5\% de la muestra (CEREZO, A. y DÍAZ, D., "El enfermo mental en el medio penitenciario español", International E-Journal of Criminal Sciences, $\mathrm{n}^{\circ}$ 10, 2016, p. 16). Una recopilación de otros estudios realizados sobre prevalencia de estos trastornos en prisión puede verse en FUENTES, M. y FERNÁNDEZ, E. M., "La esquizofrenia en el medio penitenciario", Revista de la Asociación Española de Neuropsiquiatría, Vol. 36, n 130, 2016, pp. 407 y ss. Desde otra perspectiva, analiza el fenómeno empleando una metodología cualitativa ROLDÁN BARBERO, H., “¿Adónde van los enfermos mentales que cometen delitos?”, Revista Electrónica de Estudios Penales y de la Seguridad, n $^{\circ} 5$ (2019), pp. 3 y ss.

44 Conformada por hombres con edades comprendidas entre los 18 y 75 años, castellano parlantes y con la capacidad mental suficiente para 
investigación vinieron a confirmar las principales conclusiones alcanzadas en el estudio PRECA: la tasa de prevalencia de trastorno mental encontrada en la población reclusa era 5,3 veces superior a la de la población general, la prevalencia vida era de un $90,2 \%$ de los casos (esto es, nueve de cada diez internos habían sufrido algún trastorno mental a lo largo de su existencia), y los trastornos más prevalentes resultaban ser los ocasionados por consumo de sustancias, los afectivos y los psicóticos. Por lo que respecta a los trastornos del espectro de la esquizofrenia, estos presentaban tasas significativas tanto en la medición de la prevalencia vida $(11,4 \%)$ como en la de prevalencia mes (escala en la que aparecía como el segundo trastorno en importancia-casi un 10\%-tras los episodios depresivos mayores $-12,5 \%)^{45}$.

La investigación más reciente de la que se tiene noticia sobre prevalencia de enfermedad mental en el ámbito penitenciario español constituye, probablemente, la de mayor envergadura realizada hasta el momento sobre la materia en nuestro país. La muestra de dicho estudio, cuyos resultados se han publicado en 2020, incluyó a 1328 internos de los centros penitenciarios de Castellón I, Castellón II y Valencia II que fueron derivados a la consulta de psiquiatría penitenciaria por los servicios médicos de estos centros, y los datos se obtuvieron directamente de las evaluaciones psiquiátricas realizadas a dichas personas entre julio de 2010 y octubre de $2013^{46}$. Entre los hallazgos de esta investigación

otorgar consentimiento informado, de los cuales el 96,6\% estaba en régimen de segundo grado, el $2,9 \%$ en tercer grado y el $0,6 \%$ en régimen cerrado. ZABALA BAÑOS, C., Prevalencia de trastornos mentales en prisión: Análisis de la relación con delitos y reincidencia, Madrid, Ministerio del Interior/Secretaría General Técnica, 2017, pp. 137 y ss.

45 ZABALA BAÑOS, C., Prevalencia de trastornos mentales en prisión: Análisis de la relación con delitos y reincidencia, cit., pp. 158, 197-198.

46 El mismo psiquiatra visitó cada centro cuatro veces al mes y evaluó o trató entre ocho y diez reclusos en cada consulta. El 93\% de los sujetos incluidos en la muestra eran hombres con una edad media de 36,8 años, 
destacan los siguientes: el $81,4 \%$ de los internos objeto del estudio presentaba una patología dual (trastorno por uso de sustancias junto con trastorno mental), y en el 10,5\% de los casos, las remisiones a consulta psiquiátrica estuvieron motivadas por la presencia de síntomas psicóticos; en cuanto a los diagnósticos, los de mayor prevalencia eran los trastornos de personalidad $(68,2 \%)$, seguidos de los trastornos del espectro esquizofrénico (13\%). Estos últimos pacientes (los enfermos de esquizofrenia), fueron remitidos a consulta psiquiátrica por la detección de síntomas activos de psicosis en el 43,6\% de los supuestos, lo que probablemente influye de forma significativa en el hecho de que requieran ser evaluados con más frecuencia en consultas de seguimiento que, según concluye la investigación, deberían ser más prolongadas ${ }^{47}$.

Como puede comprobarse, son varios los estudios que se han publicado sobre prevalencia de trastornos mentales en el ámbito penitenciario español, pero la diversidad de metodologías utilizadas tanto para seleccionar la muestra como para extraer los datos (historias clínicas, entrevistas, consultas psiquiátricas), hace prácticamente imposible la realización de una comparación estricta de los resultados obtenidos. No obstante, el análisis conjunto de todos ellos, puestos en relación con los datos oficiales más recientes suministrados por la Secretaría General de Instituciones Penitenciarias, permiten extraer algunas conclusiones:

nacionales españoles en un $88,1 \%$ y con una discapacidad física o mental reconocida en el 4,9\% de los casos. ARNAU, F., GARCÍA-GUERRERO, J., BENITO, A., VERA-REMARTÍNEZ, E. J., BAQUERO, A. y HARO, G., "Sociodemographic, Clinical, and Therapeutic Aspects of Penitentiary Psychiatric Consultation: Toward Integration into the General Mental Health Services", Journal of Forensic Sciences, Vol. 65, $\mathrm{n}^{\circ} 1,2020$, pp. 160-165.

47 Cfr. ARNAU, F., GARCÍA-GUERRERO, J., BENITO, A., VERAREMARTÍNEZ, E. J., BAQUERO, A. y HARO, G., "Sociodemographic, Clinical, and Therapeutic Aspects of Penitentiary Psychiatric Consultation: Toward Integration into the General Mental Health Services”, cit., pp. 161-162. 
- Aun excluyendo a los enfermos internados en los hospitales psiquiátricos penitenciarios, parece un hecho constatado que la tasa de prevalencia de trastornos mentales es muy elevada entre la población reclusa, y en todo caso significativamente superior a la existente entre la población general (probablemente unas cinco veces más alta) ${ }^{48}$.

- Según los datos oficiales, casi un tercio de los reclusos (un 27,9\%, para ser exactos) está en tratamiento con medicación psiquiátrica "y presentan un marcado deterioro a nivel físico, psíquico y social" ${ }^{49}$. Un notable porcentaje de los TMG detectados entre los internos en centros penitenciarios ordinarios corresponde a trastornos psicóticos o del espectro esquizofrénico (alrededor del 10\% de la población penitenciaria puede sufrir este tipo de trastornos) $)^{50}$.

- El consumo de sustancias tóxicas aparece relacionado de manera significativa con la enfermedad mental en todos los estudios analizados, lo que constituye asimismo un hecho oficialmente reconocido por las Instituciones Penitenciarias: "Entre los consumidores de drogas al ingreso en prisión, al 26,4\% de los consumidores de cocaína le habían diagnosticado un trastorno mental en libertad, al $36,9 \%$ de los consumidores de heroína más cocaína,

48 De acuerdo con los estudios realizados con "metodología PRECA" que fueron publicados en 2011 y 2017 (VICENS, E. et al., op. cit,, p. 328; ZABALA BAÑOS, op. cit., p. 197).

49 SECRETARÍA GENERAL DE INSTITUCIONES PENITENCIARIAS, Informe General 2018, cit., p. 242.

50 Dicha conclusión se extrae de los resultados obtenidos en los dos estudios de diseño PRECA (VICENS, E. et al., op. cit., p. 324; ZABALA BAÑOS, op. cit., p. 159) y en el reciente estudio de 2020 (ARNAU et al., op. cit., pp. 161-162). 
al 33,6\% de los consumidores de heroína, al 23,9\% de los consumidores de cannabis y al 15,9\% de los consumidores de alcohol. Y viceversa, entre los internos con enfermedad mental es frecuente el consumo de drogas: el $84,9 \%$ de los internos que han sido diagnosticados en prisión de un trastorno mental han consumido alguna vez en la vida drogas ilegales (cannabis, opiáceos, cocaína, metadona no recetada, anfetaminas, éxtasis, alucinógenos o inhalables). Si incluimos a los que han consumido tranquilizantes y alcohol, el porcentaje es aún superior. Además, el 37,9\% de los internos que están en tratamiento con medicación psiquiátrica han consumido drogas en el último mes en prisión, principalmente cannabis" 51 .

- El tratamiento médico otorgado a estos enfermos dista mucho de ser el idóneo, se ve afectado en gran medida tanto por la escasez de recursos como por la falta de coordinación entre la administración penitenciaria y los servicios de salud comunitarios y resulta, a todas luces, insuficiente. Ello es especialmente relevante en el caso de los reclusos que padecen esquizofrenia, los cuales son objeto de un seguimiento mucho menos intenso y prolongado (en el mejor de los casos, una visita cada dos meses) que el que se proporciona desde los servicios de salud mental a la población en general que sufre este tipo de dolencias (donde se recomienda realizar una visita de seguimiento mensual $)^{52}$.

51 SECRETARÍA GENERAL DE INSTITUCIONES PENITENCIARIAS, Informe General 2018, cit., p. 231.

52 Esta es una de las principales conclusiones del estudio publicado en 2020 (ARNAU, F. et al., op. cit., p. 162). 


\subsection{Programas de intervención penitenciaria para in- ternos con TMG}

Las demoledoras conclusiones que se acaban de exponer no suponen ignorar las importantes actuaciones que se han emprendido desde la administración penitenciaria para mejorar, al menos, las gravosas condiciones en las que se hallan los enfermos mentales internados en las prisiones españolas. De hecho, el primer diagnóstico de la situación llevado a cabo en el seno de Instituciones Penitenciarias en 2006 (que ya se ha comentado) sirvió para que de modo inmediato se plantearan una serie de iniciativas y estrategias encaminadas a afrontar dicha problemática. Así nace el Programa marco de Atención Integral a Enfermos Mentales en el medio penitenciario (PAIEM) ${ }^{53}$, elaborado sobre la base de objetivos preventivos, terapéuticos y de reinserción ${ }^{54}$, y lleno de buenos propósitos: "10 detectar, diagnosticar y tratar a todos los internos que sufran algún tipo de trastorno mental, y efectuar su derivación a programas de rehabilitación; $2^{\circ}$ mejorar la calidad de vida de los enfermos mentales, aumentar su autonomía personal y la adaptación al entorno; $3^{\circ}$ optimizar la reincorporación social y la derivación adecuada a un recurso socio-sanitario comunitario".

53 DIRECCIÓN GENERAL DE INSTITUCIONES PENITENCIARIAS, "Programa marco para la Atención Integral a Enfermos Mentales en Centros Penitenciarios", en MINISTERIO DEL INTERIOR, Estrategia Global de Actuación en Salud Mental, 2007. En septiembre de 2009, la Secretaría General de Instituciones Penitenciarias publicó el Protocolo de aplicación del Programa Marco de Atención Integral a Enfermos Mentales en centros penitenciarios, cuya modificación principal respecto del PAIEM consiste en establecer un único Equipo Multidisciplinar de Salud Mental, responsable de la intervención sobre el enfermo desde su detección y diagnóstico hasta su salida en libertad. Otra versión del Programa, denominada PAIEM Renovado, fue difundida en diciembre de 2013.

54 Cfr. EQUIP VINCLES SALUT, Guía para la Promoción de la Salud Mental en el Medio Penitenciario, Madrid, Ministerio del Interior/Secretaría General de Instituciones Penitenciarias, 2011, p. 13. Otras de las iniciativas emprendidas a raíz del estudio de 2006 fue la modernización de los dos hospitales psiquiátricos penitenciarios: Alicante y Sevilla. 
El PAIEM está dirigido específicamente a los enfermos mentales que, aun habiendo sido diagnosticados como tales, fueron declarados culpables de la comisión de un delito y se encuentran cumpliendo una pena privativa de libertad en un centro penitenciario de régimen ordinario; junto a ellos, el PAIEM presta asimismo atención a aquellos internos que sufren un trastorno mental sobrevenido durante su estancia en prisión, pero no obstante se considera que no cumplen los requisitos establecidos en el art. $60 \mathrm{CP}$ para suspender la ejecución de su pena. Quedan fuera de su ámbito, en cambio, los enfermos mentales considerados inimputables y peligrosos en el momento de dictarse sentencia (esto es, los sujetos a medidas de seguridad), cuyo tratamiento es objeto de atención en los programas específicos de los hospitales psiquiátricos penitenciarios ${ }^{55}$.

No obstante, a partir de algunas de las disposiciones, especialmente expresivas, contenidas en el PAIEM original puede deducirse que el estado mental ${ }^{56}$ de los reclusos sujetos a dicho Programa (los cuales, recuérdese, han debido ser declarados culpables en un proceso penal) no difiere mucho del que se podría encontrarse en el caso de los ingresados en hospitales psiquiátricos penitenciarios (que como mínimo deben tener mermadas sus capacidades de comprensión y actuación).

55 SANZ, J., GÓMEZ-PINTADO, P., RUIZ, A., POZUELO, F. y ARROYO, J. M., "Programa de Atención Integral al Enfermo mental en las prisiones españolas (PAIEM). Valoración tras cuatro años de funcionamiento", Revista Española de Sanidad Penitenciaria, n 16, 2014, p. 93.

56 Esto es, la capacidad mental que es susceptible de valoración médica mediante la evaluación del aspecto general, el comportamiento, la presencia de ideas inusuales o percepciones insólitas (como delirios o alucinaciones), el estado de ánimo y todos los aspectos de la cognición (cfr. NEWMAN, G., "Cómo evaluar el estado mental" -versión de febrero de 2018-, Manual MSD. Versión para profesionales, disponible en: https://www.msdmanuals.com/es-es/professional/trastornosneurol $\% \mathrm{C} 3 \% \mathrm{~B} 3$ gicos/examen-neurol $\% \mathrm{C} 3 \% \mathrm{~B} 3$ gico/c $\% \mathrm{C} 3 \% \mathrm{~B} 3$ mo-evaluar-el-estado-mental 
Así, entre los objetivos específicos que pueden perseguirse con el Plan Individualizado de Rehabilitación (PIR) que debe elaborarse tras la evaluación de cada enfermo recluso, la primera versión del PAIEM enumeraba los de "conseguir que recoja y se tome la medicación diaria de forma correcta (en el plazo de un mes); conseguir que sea capaz de ducharse y asearse diariamente (en el plazo de un mes); lograr que habitualmente tenga la celda limpia y ordenada (en el plazo de un mes); conseguir que no tenga comportamientos violentos (físicos y verbales); lograr que no se produzca autolesiones; ampliar el número de internos con los que establece conversaciones y realiza actividades recreativas (en el plazo de dos meses); conseguir una asistencia regular a las actividades deportivas, ocupacionales y académicas designadas (en el plazo de dos meses); lograr que mantenga por iniciativa propia entrevistas periódicas con el psicólogo, educador y trabajador social; manejar correctamente el peculio (en el plazo de dos meses); conseguir que pueda utilizar de forma autónoma el transporte público hasta llegar a su domicilio familiar (en el plazo de seis meses) $)^{57}$.

Por otro lado, y a pesar de que su ámbito de actuación excluye expresamente a los internados en hospitales psiquiátricos penitenciarios, la mayoría de las características del interno que se señalaban en el PAIEM original (y en su Protocolo de 2009) como posibles indicadores de enfermedad mental (y ante cuya detección "se ruega [al personal de la prisión] lo ponga en conocimiento del Equipo Sanitario"), parecen describir a presos que sufren TMG, particularmente trastornos del espectro esquizofrénico: "Manifestar que percibe o escucha cosas que los demás no son capaces de experimentar ('voces que le hablan'). Un sentido de sí mismo

57 DIRECCIÓN GENERAL DE INSTITUCIONES PENITENCIARIAS, "Programa marco para la Atención Integral a Enfermos Mentales en Centros Penitenciarios", cit., p. 19. Este listado tan detallado de objetivos fue suprimido del texto del Protocolo de aplicación del PAIEM de 2009. 
exageradamente engrandecido ('creer tener habilidades especiales' o 'haber hecho grandes descubrimientos', etc.). Lenguaje incoherente o disgregado o escasamente comprensible. Manifestar conductas extrañas sin sentido aparente o desorganizado. Apariencia extraña, mímica y contacto interpersonal fuera de la normalidad, por ausencia o por exceso. Elevada impulsividad, apenas puede estar quieto, se enfada, amenaza o se irrita con enorme facilidad. No se adapta a la vida de los módulos. Grave deterioro en el cuidado personal: aseo y celda. Haber cumplido una medida de seguridad en Centro Especial. Historial de tratamiento psiquiátrico o de ingresos en unidades psiquiátricas de hospitalización. Informes de fuentes externas o familiares que revelen tratamiento psiquiátrico más o menos prolongado en el tiempo. Recibir prestación económica o algún tipo de pensión por tener reconocida algún tipo de minusvalía psíquica"s8.

Lo anterior aparece corroborado por el propio Gobierno español en una respuesta dada en julio de 2019 a una pregunta parlamentaria: "Alrededor del 4,2\% de los internos en centros penitenciarios presentan Trastorno Mental Grave (TMG), colectivo al cual va dirigido el Programa de Atención Integral a Enfermos Mentales (PAIEM)". De los 1834 internos atendidos por el PAIEM, "el 38\% presenta patología dual, el 37,3\% trastorno psicótico, el 29,7\% trastorno de personalidad, el 16,7\% trastorno afectivo y el $12,4 \%$ otro tipo de trastorno". En esa misma respuesta el Gobierno reconocía que en los centros penitenciarios de cumplimiento ordinario "no existen salas específicas para albergar en exclusiva a los enfermos mentales", y que alrededor del $16 \%$ de los internos con TMG residen preferentemente en las enfermerías de dichos centros, al persistir conductas de riesgo y disruptivas y

58 DIRECCIÓN GENERAL DE INSTITUCIONES PENITENCIARIAS, "Programa marco para la Atención Integral a Enfermos Mentales en Centros Penitenciarios", cit., p. 33. Estas características desaparecen de la redacción del PAIEM Renovado de 2013. 
síntomas positivos que interfieren significativamente con el funcionamiento diario" $" 59$.

Algunas de las conclusiones obtenidas en las investigaciones que han evaluado los resultados obtenidos por el PAIEM desde su implantación no son alentadoras. Así, en un estudio publicado en 2014 y confeccionado a partir de las encuestas realizadas al $90 \%$ de los profesionales que participan en el Programa, se señala, por un lado, que la actuación llevada a cabo ante un incidente regimental protagonizado por un interno incluido en el PAIEM consiste en la redacción de un parte disciplinario por el funcionario de vigilancia en más del 64\% de los casos, siendo muy minoritarios $(17,7 \%)$ aquellos supuestos en los que la Comisión Disciplinaria del centro valora un informe expresamente elaborado por el Equipo PAIEM o por el propio funcionario; por otro lado, solo en un tercio de los centros participantes en el PAIEM se realiza contacto personal y directo con las familias de los enfermos (en algunos no se realiza contacto familiar de ningún tipo), y solo un tercio de estos internos son derivados adecuadamente a los recursos comunitarios que precisan tras su excarcelación, de modo que, "al no establecerse contactos previos ni con las familias, ni con los centros comunitarios de salud mental, ni con las instituciones y entidades de acogida, se reduce gravemente la continuidad de cuidados en la red de atención socio-sanitaria comunitaria y el apoyo de la red familiar y social" 60 .

Precisamente para favorecer la prolongación del tratamiento y la integración del enfermo con TMG tras su excarcelación, la Secretaría General de Instituciones Penitenciarias

59 Respuesta del Gobierno de 9 de julio de 2019 a la pregunta escrita 184/284, de 18 de junio de 2019 del Diputado Jon Iñarritu García. Disponible en: http://www.congreso.es/entradap/113p/e0/e_0002492_n_000.pdf

60 SANZ, J., GÓMEZ-PINTADO, P., RUIZ, A., POZUELO, F. y ARROYO, J. M., "Programa de Atención Integral al Enfermo mental en las prisiones españolas (PAIEM). Valoración tras cuatro años de funcionamiento", cit., pp. 94-96 y 99. 
implementó a lo largo del bienio 2014-2015 los Programas de Unidades Puente en los Centros de Inserción Social (CIS), con los que se pretende dar continuidad al PAIEM durante el cumplimiento de la condena en la modalidad de régimen abierto y libertad condicional. Dentro de este escenario se enmarcan proyectos como el Programa Puente de Mediación Social (que se lleva a cabo en una veintena de CIS y requiere para su puerta en marcha de la intervención de una organización no gubernamental o una entidad colaboradora, que debe formar parte del equipo multidisciplinar) ${ }^{61}$, y el Programa Puente Extendido (creado para quienes deben cumplir penas o medidas alternativas gestionadas desde los CIS $^{62}$ como consecuencia de la suspensión de una pena privativa de libertad), con el fin de facilitar la detección temprana de condenados con TMG, evitar incumplimientos y, en definitiva, impedir el consiguiente ingreso en prisión ${ }^{63}$.

61 A 31 de diciembre de 2018, participaban en este Programa Puente 143 internos (SECRETARÍA GENERAL DE INSTITUCIONES PENITENCIARIAS, Informe General 2018, cit., pp. 138-140).

62 Conforme a lo dispuesto en el Real Decreto 840/2011, de 17 de junio, por el que se establecen las circunstancias de ejecución de las penas de trabajo en beneficio de la comunidad y de localización permanente en centro penitenciario, de determinadas medidas de seguridad, así como de la suspensión de la ejecución de las penas privativas de libertad y sustitución de penas.

63 MATEO SOLER, M., GÓMEZ DE TOJEIRO ROCE, J., ÁlVAREZ CRESPO, R., FERNÁNDEZ MODAMIO, M., BENGOECHEA IBACETA, J., FERNÁNDEZ IGLESIAS, P., GURRÍA FLORES, G., GIL SANZ, D., RÍOS MARTÍNEZ, J. y GAITE PINDADO, L., "Programa Puente Extendido. Salud mental en penas y medidas alternativas", cit., p. 13. En 2018 este Programa se encontraba plenamente implantado en 11 de los 55 Servicios de Gestión de Penas y Medidas Alternativas (SECRETARÍA GENERAL DE INSTITUCIONES PENITENCIARIAS, Informe General 2018, cit., pp. 173-174). 


\section{La valoración judicial del TMG en el orden penal: posibles calificaciones y sus consecuencias en el ámbito penitenciario}

Con todas sus luces y sus sombras, parece que la reforma psiquiátrica española, junto a las investigaciones que ponen de manifiesto las altas tasas de prevalencia de enfermedad mental en nuestro sistema carcelario, han propiciado un notable cambio de enfoque en la administración penitenciaria en los últimos años: a pesar de los problemas competenciales y la generalizada escasez de recursos, la elaboración y puesta en marcha de programas específicos para personas con TMG internadas en las prisiones demuestra que la realidad penitenciaria ha evolucionado desde la desidia de décadas pasadas hacia una cierta preocupación por paliar el problema. Esa evolución no se percibe, sin embargo, con tanta nitidez entre los ciudadanos en general y los aplicadores del Derecho en particular, que parecen seguir anclados en determinados prejuicios que contribuyen, desde tiempos inmemoriales, a la estigmatización de los enfermos mentales ${ }^{64}$.

En efecto, como señala QUINTERO OLIVARES, entre la ciudadanía está más o menos o extendida la convicción de que el declarado judicialmente como "loco", se "libra" del proceso penal y por consiguiente de la represión punitiva. Quizá esta sea una de las razones por las que "el enfermo mental en el sistema penal entendido en sentido amplio (delitos, procesos, internamientos) aparece como uno de los escollos en los que tropieza la a veces pretendida evolución de ese sistema, que con frecuencia se muestra incapaz -las razones son de muy diversa naturaleza- de dar una respuesta

64 Los prejuicios, temores o reservas contra los enfermos mentales presentes en buena parte de la ciudadanía pueden deslizarse al ámbito judicial, entre otras vías, a través de la institución del Jurado, el cual, en el ejercicio de sus competencias jurisdiccionales "no se limita a decidir si el hecho está o no probado, sino que valora aspectos como son los componentes normativos que dan lugar a la exención o no de la responsabilidad penal" (cfr. Exposición de Motivos de la LO 5/1995, de 22 de mayo, del Tribunal del Jurado). 
coherente con los propios diagnósticos y criterios que aceptan y usan los Tribunales [...]. Cuando se alude a la condición de enfermo mental, o se señala una alteración psíquica en un sujeto, que impide declararle responsable de sus actos, se abre un debate viejo y quizás eterno: la comprensión y tolerancia o, por el contrario, el recelo y la desconfianza ante la locura" ${ }^{65}$. Y ese recelo y desconfianza pueden hacer que, en un número nada desdeñable de casos, la balanza se incline a favor del ingreso en un establecimiento penitenciario de la persona con TMG que ha cometido un hecho delictivo (ya sea en forma de pena, ya de medida de seguridad ${ }^{66}$.

En cualquier caso, debe destacarse la "flexibilidad" que caracteriza a la fórmula acogida en el art. 20.1 CP (que permanece inalterada desde 1995) para valorar la imputabilidad o inimputabilidad de quien padece un trastorno mental, y con la que se pretendía propiciar un diálogo vivo entre el Derecho y las ciencias de la conducta (cuyos conocimientos sobre los diversos síndromes psicopatológicos están sometidos a constante revisión $)^{67}$. Dicha fórmula permite, en

65 QUINTERO OLIVARES, G., Locos y culpables, Pamplona, Aranzadi, 1999 , pp. 36 y 38.

66 Y ello a pesar de que en un número muy elevado de supuestos es posible adoptar otro tipo de medidas "que pueden resultar más efectivas que el encarcelamiento, porque proporcionan una mayor seguridad a la hora de evitar la reincidencia del delito. Esto es especialmente frecuente en 7 de cada 10 delincuentes que sufren trastornos mentales y/o adicción a drogas y se beneficiarían de programas apropiados en su comunidad evitando una conducta delictiva de baja intensidad, que es la que con mayor frecuencia han realizado" (SECRETARÍA GENERAL DE INSTITUCIONES PENITENCIARIAS, Hospitales Psiquiátricos dependientes de la Administración Penitenciaria. Propuesta de Acción, cit., p. 3.

67 La flexibilidad o relatividad de la fórmula contenida en el art. 20.1 CP ha sido en general acogida positivamente, en la medida en que favorece "una actitud de diálogo constructivo en la que se evite tanto una decimonónica suspicacia hacia «lo científico» (no olvidemos que la introducción de los médicos forenses en el proceso penal fue en el siglo XIX una «victoria de la razón») como una actitud acomplejada frente a la prepotencia en que puedan incurrir ciertos representantes del «poder médico»" (TAMARIT SUMALLA, J. M., "Culpabilidad, maldad 
definitiva, basar el juicio sobre la capacidad de culpabilidad en una serie factores ontológicos-causales y psicológiconormativos que deben ser tenidos en cuenta conjuntamente a la hora de determinar si el sujeto que es enjuiciado por la comisión de un delito, "a causa de cualquier anomalía o alteración psíquica", podía o no "comprender la ilicitud del hecho o actuar conforme a esa comprensión".

El carácter relativo de esta "fórmula mixta"68 (la cual, al menos en teoría, debería haber producido una ampliación del radio de acción de la exención ${ }^{69}$ ha permitido alejar a la inimputabilidad de sus bases ontológicas y vincularla más estrechamente al juicio normativo (que, como tal, puede ser cambiante) sobre las capacidades de comprensión y de actuación del sujeto, lo que a la postre plantea todo un abanico de posibilidades en el enjuiciamiento penal del enfermo mental: "Podrá, en fin, suceder que además de loco e inimputable, se pueda ser loco y culpable, loco e imputable, loco y no culpable" 70 .

Este planteamiento ha sido asumido de forma decidida y reiterada por la jurisprudencia de los últimos años, la

e imputabilidad: aportaciones de la dogmática penal a la cultura jurídica europea", Revista de Derecho Penal y Criminología, $2^{\mathrm{a}}$ Época, $\mathrm{n}^{\mathrm{o}}$ 17, 2006, pp. 207-208). Sobre el procedimiento a seguir para realizar el informe de imputabilidad desde el punto de vista médico, véase por ejemplo CHECA GONZÁLEZ, M. J., Manual práctico de Psiquiatría Forense, Barcelona, Elsevier Masson, 2010, pp. 207 y ss.

68 O fórmula "biológico-psicológica", que vino a sustituir a la de base exclusivamente biológica, empleada por el art. 8.1 CP73 ("Están exentos de responsabilidad criminal: $1{ }^{\circ}$ El enajenado...”). Cfr. MIR PUIG, S., Derecho Penal. Parte General, $10^{\mathrm{a}}$ ed., Barcelona, Reppertor, 2016, pp. 586-587. Sobre el régimen de la enajenación mental en el sistema punitivo anterior a 1995, véase por ejemplo CARBONELL MATEU, J. C., GÓMEZ COLOMER, J. L. y MENGUAL I LULL, J. B., Enfermedad mental y delito. Aspectos psiquiátricos, penales y procesales, Madrid, Civitas, 1987.

69 MIR PUIG, S., Derecho Penal. Parte General, cit., pp. 586

70 QUINTERO OLIVARES, G., Locos y culpables, cit., pp. 41-42. 
cual insiste en la necesidad de constatar la existencia de los dos elementos a los que hace referencia el art. 20.1 CP (esto es, el elemento "biopatológico" y el elemento "psicológiconormativo"), a pesar de reconocer las dificultades que suscita la valoración del segundo frente a la relativa "facilidad" con que puede probarse la presencia del primero. En todo caso, se señala, dada la doble exigencia legal de causa biopatológica y efecto psicológico, "no es suficiente el diagnóstico de la enfermedad, resultando imprescindible la prueba efectiva de la afectación de las facultades mentales en el caso concreto", lo que deberá realizarse conforme al siguiente proceso: en primer lugar, "se analiza y examina el material probatorio atinente al elemento biopatológico, se establece el grado y la intensidad del padecimiento psíquico"; posteriormente, "se extrae de forma directa de tal base biopatológica la conclusión sobre si el autor de la conducta delictiva actuó comprendiendo la ilicitud del hecho y con posibilidad de actuar conforme a esa comprensión, o, en su caso, con una comprensión o una capacidad de actuación limitadas o excluidas" "71.

Como puede comprobarse, este proceso deductivo "genérico" elaborado por la jurisprudencia penal más reciente para valorar las anomalías o alteraciones psíquicas y su relativa incidencia en la inimputabilidad o imputabilidad de quien las padece, no difiere de forma significativa del que venían aplicando los tribunales en la última época de vigencia del texto punitivo anterior. Sin embargo, el hecho de que el número de reclusos en centros penitenciarios ordinarios aquejados de TMG no haya dejado de incrementarse en los últimos años, obliga a plantearse como hipótesis la posibilidad de que el tratamiento jurídico penal otorgado a las personas con trastornos mentales en el art. 20.1 CP (teóricamente inspirado en una fórmula más flexible que la recogida en su precedente normativo) haya sido reconducido, en su

$71 \mathrm{Al}$ respecto, véase la STS 348/2019, de 4 de julio, y demás jurisprudencia allí citada. 
aplicación judicial, a un esquema mucho más rígido; lo que, paradójicamente, podría estar provocando una reducción de su radio de acción y el consecuente incremento del número de condenados con TMG.

Para comprobar dicha hipótesis, se ha realizado un estudio de 105 resoluciones judiciales, dictadas por la Sala de lo Penal del Tribunal Supremo entre el 1 de enero de 2015 y el 31 de julio de $2020^{72}$, que incluyen pronunciamientos sobre la mayor o menor relevancia del trastorno mental del acusado a la hora de determinar las consecuencias penales de su comportamiento ${ }^{73}$. Aunque los resultados de dicho estudio son analizados en las siguientes páginas, pueden exponerse ahora algunas conclusiones generales:

- Tan solo la constatación de determinadas patologías graves (mayoritariamente, las pertenecientes al

72 Puede verse un estudio jurisprudencial de características similares, aunque elaborado conforme a una metodología muy diferente, en ROMERO ÁLVAREZ, J. J. y MOLINA MARTÍN, J. D., "Esquizofrenia y delincuencia: análisis de la jurisprudencia del Tribunal Supremo entre 2008 y 2018", Revista Internacional Jurídica y Empresarial, $\mathrm{n}^{\circ} 2,2019$, pp. 81 y ss.

73 La selección de las concretas resoluciones incluidas en el estudio (que pueden consultarse en el Anexo jurisprudencial incluido al final de este trabajo) se ha realizado del siguiente modo: a) en primer lugar, se ha llevado a cabo una búsqueda en la base de datos Westlaw de los autos y sentencias de la Sala de lo Penal del Tribunal Supremo, dictados entre el 1 de enero de 2015 y el 31 de julio de 2020, que aparecieran listados en las voces "anomalía o alteración psíquica" (78 resultados), "esquizofrenia" (86 resultados) y "trastorno mental grave" (4 resultados); b) el cotejo de dichos resultados (para evitar duplicidades) y su filtrado (para excluir aquellas resoluciones que mencionaran alguna de esas voces en otros contextos -por ejemplo, si quien padece la "esquizofrenia" es la víctima) produjo un total de 125 resoluciones; c) fueron asimismo descartadas del listado jurisprudencial que es objeto de análisis otras dos resoluciones (por razones de nulidad procesal o atipicidad), así como todas aquellas en las que no constaba trastorno mental alguno en el acerbo probatorio (dicho trastorno fue simplemente alegado por la defensa). Como consecuencia de lo anterior, la muestra definitiva está conformada por un total de 105 resoluciones (38 autos y 67 sentencias). 
espectro de la esquizofrenia) provoca la posterior valoración del denominado elemento psicológiconormativo, con el fin de determinar la capacidad de culpabilidad de los sujetos que la padecen.

- Para proceder a dicha valoración (y a su correspondiente graduación en términos de inimputabilidad, imputabilidad disminuida o reducción de la culpabilidad a través de la aplicación de una atenuante) suele requerirse la manifestación de síntomas psicóticos (delirios o alucinaciones) en el preciso instante de la comisión de los hechos enjuiciados (lo cual resulta, en la mayoría de los casos, imposible de probar).

- La prueba del componente "causal-cronológico" del denominado factor biológico no solo determina la posibilidad de apreciar la inimputabilidad plena del sujeto, sino que también condiciona la hipotética graduación de la culpabilidad de la persona que padece TMG (eximente incompleta por semi-imputabilidad, o atenuante analógica).

Todo lo anterior se ve reflejado en la doctrina que el Tribunal Supremo, según afirma, viene aplicando de forma reiterada a los trastornos del espectro esquizofrénico, en cuya virtud se diferencian las siguientes situaciones:

a) Si el hecho delictivo se ha producido bajo los efectos del brote esquizofrénico, resultará de aplicación la eximente completa del art. 20.1 CP.

b) Si el acusado no actuó bajo dicho brote, pero las concretas circunstancias del hecho revelan un "comportamiento anómalo" que puede atribuirse a dicha enfermedad, deberá aplicarse la eximente incompleta del art. 21.1 CP. 
c) Finalmente, si en el supuesto concreto no hubo brote y tampoco se apreció un comportamiento extraño derivado de la enfermedad, la presencia de un "residuo patológico" denominado "defecto esquizofrénico" (o esquizofrenia residual) fundamentará la aplicación de una atenuante analógica conforme a lo establecido en el art. 21.7 $\mathrm{CP}^{74}$.

\subsection{La persona con TMG declarada inimputable}

Tan solo 11 de las 105 resoluciones judiciales analizadas afirman la completa inimputabilidad de la persona aquejada de TMG. Dicha declaración está fundamentada en la presencia de síntomas psicóticos y en el diagnóstico de un trastorno perteneciente al espectro de la esquizofrenia en 10 de los $\operatorname{casos}^{75}$.

La aplicación de la eximente completa prevista en el art. 20.1 CP puede implicar la imposición de una medida de seguridad, siempre que "del hecho y de las circunstancias personales del sujeto pueda deducirse un pronóstico de comportamiento futuro que revele la probabilidad de comisión de nuevos delitos" (art. 95.1.2 $\left.{ }^{\circ} \mathrm{CP}\right)^{76}$. El segundo párrafo del mismo artículo aclara que, cuando la pena que hubiera podido imponerse por el delito cometido no fuera privativa de libertad, solo podrá acordarse alguna o algunas de las medidas previs-

74 Al respecto, véase la STS 154/2020, de 18 de mayo, y demás jurisprudencia allí citada.

75 En el caso restante, el diagnóstico fue de "demencia mixta frontotemporal de predominio frontal y con componente vascular, de carácter progresivo y permanente" -STS 448/2016, de 25 de mayo de 2016.

76 Dicho precepto insiste en lo ya afirmado en el art. $6 \mathrm{CP}$, en el que con carácter general se declara: "1. Las medidas de seguridad se fundamentan en la peligrosidad criminal del sujeto al que se impongan, exteriorizada en la comisión de un hecho previsto como delito. 2. Las medidas de seguridad no pueden resultar ni más gravosas ni de mayor duración que la pena abstractamente aplicable al hecho cometido, ni exceder el límite de lo necesario para prevenir la peligrosidad del autor". 
tas en el art. $96.3 \mathrm{CP}^{77}$. Ello sin embargo no debe interpretarse como una obligación de imponer al inimputable por TMG una medida de internamiento en el resto de supuestos, pues el art. $101 \mathrm{CP}$ prevé la posibilidad de aplicarle "cualquier otra de las medidas previstas en el apartado 3 del artículo 96”. Es más: conforme al mismo precepto, solo podrá imponérsele una medida de internamiento "si fuere necesaria, (...) para tratamiento médico o educación especial en un establecimiento adecuado al tipo de anomalía o alteración psíquica que se aprecie", y la duración de dicho internamiento "no podrá exceder del tiempo que habría durado la pena privativa de libertad, si hubiera sido declarado responsable el sujeto", debiendo a tal efecto el Juez o Tribunal fijar en la sentencia ese límite máximo.

Como puede comprobarse, la legislación aplicable parece establecer de forma nítida los requisitos y condiciones que deben concurrir para aplicar una sanción penal (también lo son las medidas de seguridad) a personas que, si bien han cometido hechos calificados como delitos, han sido declaradas inimputables a consecuencia de su TMG: a) resulta imperativa la existencia de un pronóstico de peligrosidad (entendida como probabilidad de comisión de nuevos delitos en el futuro), el cual deberá deducirse tanto del hecho como de las circunstancias personales del sujeto; b) una vez deducido dicho pronóstico, deberá valorarse la necesidad de imponer una medida de seguridad (atendiendo al tratamiento médico o de educación especial que requiera el enfermo), que podrá ser o no privativa de libertad; c) en caso de resultar necesaria, conforme a los criterios mencionados, la imposición de una medida de seguridad privativa de libertad, su cumplimiento deberá realizarse en un establecimiento adecuado al tipo de anomalía o alteración psíquica del declarado inimputable, y su duración no podrá exceder el límite de lo necesario para prevenir su peligrosidad.

77 Esto es, medidas que no son calificadas como "privativas de libertad", aunque entre ellas se encuentran la libertad vigilada y la custodia familiar. 
En relación con el juicio relativo a la peligrosidad del sujeto, la jurisprudencia ha afirmado en alguna ocasión que "no puede fundarse en un puro decisionismo intuitivo del operador judicial, sino que debe sustentarse en argumentos científicos contrastados y admitidos por la Comunidad científica que permitan aventurar, sin que sea necesario alcanzar la certeza propia de las ciencias naturales, la posible actuación futura del afectado"78; tal afirmación (obvia, por lo demás) resulta no obstante demasiado genérica a la hora de explicar cómo debe procederse para emitir un juicio que, como todos los que se basan en un "pronóstico", presenta problemas ciertos de seguridad jurídica ${ }^{79}$.

En efecto, qué concretos factores deben tenerse en cuenta a la hora de valorar la peligrosidad del sujeto declarado inimputable, qué relevancia ha de otorgarse a cada uno de ellos y conforme a qué metodología, son cuestiones que distan mucho de estar claras. Así por ejemplo, la gravedad del hecho cometido (más patente en un homicidio o en un asesinato) parece un dato excesivamente pobre por sí solo a la hora de valorar la peligrosidad del sujeto declarado inim-

78 STS 482/2010, de 4 de mayo; en este mismo sentido, SSTSJ Cataluña 74/2019, de 30 de mayo, y 94/2019, de 9 de julio; SAP Madrid 115/2016, de 7 de marzo; SSAP Gran Canaria 338/2018, de 24 de septiembre, y 445/2018, de 30 de noviembre; SSAP Barcelona 396/2018, de 17 de julio, $528 / 2018$, de 2 de noviembre, y 24/2019, de 19 de julio; AAP Barcelona 345/2020, de 3 de junio.

79 Al respecto, véase por ejemplo GARCÍA ARÁN, M., Fundamentos y aplicación de penas y medidas de seguridad en el Código Penal de 1995, Pamplona, Aranzadi, 1997, p. 132; NARVÁEZ RODRÍGUEZ, A., "Las medidas de seguridad", Estudios Jurídicos del Ministerio Fiscal, n 3, 1999, p. 385; JORGE BARREIRO, Agustín, "El enfermo mental delincuente y peligroso ante el CP de 1995", Revista de Derecho Penal y Criminología, $2^{\mathrm{a}}$ Época, $\mathrm{n}^{\circ} 6,2000$, p. 183. Especialmente ilustrativa al respecto, MARTÍNEZ GARAY, L., "La incertidumbre de los pronósticos de peligrosidad: consecuencias para la dogmática de las medidas de seguridad", InDret, 2/2014, p. 52: "nos equivocamos más veces que las que acertamos en nuestras predicciones de peligrosidad, llegando en ocasiones las tasas de falsos positivos al 70 o al $80 \%$. 
putable por TMG, pues la misma gravedad presentan los homicidios y asesinatos que son cometidos por individuos plenamente responsables ${ }^{80}$. Por otro lado, multitud de estudios parecen avalar que la persona que padece TMG, si es debidamente tratada de su enfermedad, no tiene por qué presentar de modo automático un nivel de agresividad superior al de un individuo "normal", el cual también puede volverse proclive a una mayor peligrosidad (comisión o reiteración de delitos) por la concurrencia de los mismos factores que influyen como desencadenantes de la violencia en el sujeto con TMG (consumo o abuso de sustancias tóxicas, antecedentes policiales, desarraigo familiar y social, etc. $)^{81}$. Concretamente en relación con los trastornos del espectro de la esquizofrenia, aparece como uno de los factores que con mayor probabilidad pueden predecir comportamientos delictivos futuros la ausencia de tratamiento médico o la falta de adherencia al prescrito ${ }^{82}$, pero deducir de este único dato la

80 Cfr. QUINTERO OLIVARES G., Locos y culpables, cit., p. 112.

81 "A pesar de los estereotipos, la poca literatura revisada en el ámbito penitenciario indica que los reclusos con problemas mentales no tienen estadísticamente mayor riesgo de ser violentos que aquellos con problemas mentales en la población general" (ALTAMIRANO ARGUDO, Z., El bienestar psicológico en prisión: Antecedentes y consecuencias, Tesis Doctoral, Universidad Autónoma de Madrid, 2013, p. 172). Así parece demostrarlo el estudio de MONAHAN, J., STEADMAN, H. J., ROBBINS, P. C., APPELBAUM, P., BANKS, S., GRISSO, T., HEILBRUN, K., MULVEY, E. P., ROTH, L. y SILVER, E., "An Actuarial Model of Violence Risk Assesment for Persons With Mental Disorders", Psychiatric Services, Vol. 56, n 7, 2005, pp. 810 y ss.

82 Existen numerosos estudios sobre la relación del comportamiento violento y los trastornos esquizoides (una revisión de tales estudios puede verse en ZABALA BAÑOS, C., Prevalencia de trastornos mentales en prisión: Análisis de la relación con delitos y reincidencia, cit., pp. 117122). La mayoría divergen en sus conclusiones (probablemente por el diferente método seguido y los sesgos de sus respectivas muestras), pero en todo caso parece haber una cierta unanimidad en señalar que la probabilidad de comisión de delitos violentos aumenta de forma significativa con dos factores: el diagnóstico comórbido por abuso de sustancias (alcohol y drogas) y la falta de adherencia a las terapias psicológicas y 
peligrosidad criminal del psicótico o esquizofrénico infractor puede llevarnos a una conclusión ciertamente incómoda: la intervención punitiva se revelaría como el mecanismo sustitutivo de un sistema asistencial y sanitario fallido.

Lo anterior pretende ilustrar algunas de las dificultades a las que se enfrenta la elaboración del pronóstico de peligrosidad de la persona con TMG, dificultades que han tratado de solventarse, con mayor o menor acierto, a través de diversos métodos de prognosis criminal de carácter científico (como los basados en el estudio de la personalidad del enjuiciado, los denominados "estadísticos" que emplean tablas de predicción, o los mixtos, que tratan de soslayar los defectos de los dos anteriores ${ }^{83}$. Sin embargo, la mayoría de las resoluciones analizadas parecen decantarse tácitamente por un método más bien "intuitivo" 84 , en el que se revelan como

al tratamiento farmacológico. Uno de los estudios más recientes sobre el incremento del riesgo de comportamientos violentos debido a mala adherencia a la medicación puede verse en BUCHANAN, A., SINT, K., SWANSON, J., ROSENHECK, R., "Correlates of Future Violence in People Being Treated for Schizophrenia", American Journal of Psychiatry, Vol. 176, issue 9, 2019, pp. 694 y ss. Sobre la influencia de ese mismo factor en la reincidencia delictiva de individuos con trastornos del espectro esquizofrénico, LAMBERTI, J. S, KATSETOS, V., JACOBOWITZ, D. B. y WEISMAN, R. L., "Psychosis, Mania and Criminal Recidivism: Associations and Implications for Prevention", Harvard Review of Psychiatry, Vol. 28, issue 3, 2020, pp. 179 y ss.

83 Sobre dichos métodos de prognosis criminal, véase por ejemplo MATEO AYALA, E. J., La medida de seguridad de internamiento psiquiátrico. Su ejecución y control, Madrid, EDERSA, 2004, pp. 67-68; URRUELA MORA, A., Las medidas de seguridad y la reinserción social en la actualidad. Especial consideración de las consecuencias jurídico-penales aplicables a sujetos afectos de anomalía o alteración psíquica, Granada, Comares, 2009, pp. 72 y ss. Específicamente sobre las nuevas herramientas estructuradas de estimación del riesgo, MARTÍNEZ GARAY, L.; MONTES SUAY, F., "El uso de valoraciones del riesgo de violencia en Derecho Penal: algunas cautelas necesarias", InDret, 2/2018, pp. 5 y ss.

84 Un método que, como señala MATEO AYALA, es el más difundido entre la praxis judicial, pero resulta poco fiable, "con el consiguiente peligro de arbitrariedad, discriminación e indulgencia generalizadas por 
verdaderos indicadores de la peligrosidad del enjuiciado con TMG el propio trastorno mental junto con la gravedad de la conducta delictiva realizada; de hecho, todos los relatos fácticos de las 11 resoluciones que declaran la inimputabilidad de la persona acusada incluyen delitos contra bienes eminentemente personales -asesinato u homicidio, lesiones, agresiones sexuales- o bien delitos de peligro para la vida o salud de las personas -incendio).

De forma paralela, la naturaleza de los hechos cometidos, unido a las características del TMG diagnosticado (datos que, se presume, convierten a la persona en "peligrosa") vienen a fundamentar en la mayoría de los casos, como si de una imperiosa necesidad se tratara, no solo la clase de medida de seguridad aplicable a estos inimputables (internamiento, en 10 de los 11 casos de exención completa analizados), sino también el tipo de establecimiento en el que debe cumplirse $^{85}$ (psiquiátrico penitenciario, en ocho de los 10 casos en los que se impuso el internamiento). La aplicación de tales medidas se acuerda así de forma prácticamente automática (en algunos casos, desconociendo incluso lo afirmado por los mismos peritos psiquiatras que diagnosticaron o trataron

parte de quien emite el juicio" (La medida de seguridad de internamiento psiquiátrico, cit., p. 67).

$85 \mathrm{Al}$ respecto, véase por ejemplo la STS 526/2018, de 5 de noviembre, que rechaza la petición de la defensa de que el cumplimiento de la medida de internamiento decretada se llevara a cabo en un psiquiátrico "civil" conforme a los siguientes argumentos: "el grado de peligrosidad puesto de relieve por el recurrente con sus actos homicidas es muy elevado, lo que determina que la medida a imponer tiene que ser exquisitamente seleccionada para controlar los gravísimos riesgos que genera una persona con unos padecimientos psíquicos que pueden derivar en nuevas conductas agresivas para la vida e integridad de terceras personas. Por lo cual, no se considera desproporcionado ni desmesurado que el Tribunal de instancia elija un centro en el que, cuando menos en una primera fase, tenga unos medios que permitan un control exhaustivo de los movimientos del acusado, sin dejar abierta ninguna opción a una posible fuga del interno que pudiera generar nuevos daños personales irreparables para cualquier ciudadano que estuviera en su radio de acción”. 
el TMG del paciente durante su internamiento preventivo), a partir de un enfoque que parece más centrado en la peligrosidad social del enfermo que en su peligrosidad criminal. Esto es lo que puede deducirse de lo declarado por el Tribunal Supremo: "la medida de seguridad no se impone -sin más- como un remedio terapéutico para el enfermo mental, inimputable penalmente", pues la decisión de imponerla (que "es eminentemente judicial, no médica ni terapéutica") está orientada "a una doble finalidad: a) la protección de la sociedad frente a los riesgos que represente el afectado por la medida; y b) la protección del propio afectado destinatario del tratamiento médico-terapéutico, en la medida en que puede servir para controlar sus impulsos criminales y hacer una vida normalizada" $"$.

A pesar de la vigencia teórica del principio de individualización conforme a la peligrosidad del sujeto ${ }^{87}$, la "necesidad social" de la medida de seguridad viene a justificar, asimismo, la imposición sistemática del internamiento en psiquiátrico penitenciario en su duración máxima (en las resoluciones judiciales analizadas, dicha duración oscila entre los 10 y los 40 años); tope máximo de cumplimiento que se calcula a partir del límite superior de la correspondiente sanción penal en abstracto, y en cuya imposición, además, el órgano juzgador no está sujeto al principio acusatorio ${ }^{88}$. Es

86 STS 34/2020, de 6 de febrero.

87 Cfr. STS 34/2020, de 6 de febrero.

88 ATS 635/2017, de 23 de marzo: "la adopción de las medidas de seguridad en los supuestos de alteración de la capacidad de culpabilidad escapa a las exigencias y presupuestos asociados al principio acusatorio (...) concurriendo la situación de peligrosidad-circunstancias personales del sujeto de las que pueda deducirse un pronóstico de comportamiento futuro que revele la probabilidad de comisión de nuevos delitos-, (...) la adopción de la medida se revela como necesaria y consecuencia de aquélla, sin estar sujeta su adopción a petición del Ministerio Fiscal, pues el principio acusatorio no puede regir en relación con las medidas de seguridad, consecuencia de la peligrosidad del sujeto, como si se tratase de la imposición de una pena, sistema dual que opera en planos distintos". 
cierto que las resoluciones hacen con cierta frecuencia alusión a las posibilidades que legalmente existen para modificar la naturaleza o duración de la medida de seguridad durante su ejecución ${ }^{89}$ (arts. 97 y $98 \mathrm{CP}$ ), pero también lo es que, en la práctica, no son pocos los obstáculos que se ponen a la revisión de la medida desde los propios órganos judiciales encargados de aplicar tales preceptos (así por ejemplo, resultará imposible obtener el informe de vinculación familiar que suele ser requerido judicialmente a tales efectos cuando el hecho delictivo haya tenido lugar, precisamente, en ese ámbito). De este modo, lo que originariamente se concibió como una garantía ${ }^{90}$ para el sujeto declarado inimputable por su alteración o anomalía psíquica (esto es, el establecimiento de límites ciertos al cumplimiento de la medida de seguridad impuesta, con el fin de proscribir los internamientos indefinidos), se ha convertido en un medio de indudable eficacia para mantenerlo recluido durante el mayor tiempo posible.

Entre las dificultades a las que se enfrenta la sustitución o suspensión de la medida de seguridad de internamiento cuando disminuye la peligrosidad del inimputable por TMG, destacan la escasez de recursos comunitarios "extra muros" para acoger a estos enfermos y la resistencia pertinaz que manifiestan los servicios socio-sanitarios autonómicos a

89 Cfr. STS 705/2017, de 25 de octubre: "Si la pena ha de ser proporcionada al delito, la medida de seguridad se individualiza según la peligrosidad del sujeto (...). Por consiguiente, tanto la fijación de un periodo máximo de duración de la medida como el control y seguimiento de su aplicación con arreglo a la necesidad y proporcionalidad de los fines que cumplimenta son dos garantías fundamentales de nuestro sistema penal para una aplicación de las medidas de seguridad acorde con los valores constitucionales. De ahí la importancia de que se resalten ambas garantías en las resoluciones judiciales que se dicten en los supuestos en que la pena no ha de operar y sí en cambio las medidas de seguridad".

90 Derivada del principio de proporcionalidad establecido en el art. 6.2 CP para las medidas de seguridad en general y en art. $101 \mathrm{CP}$ para las medidas de internamiento en particular. $\mathrm{Al}$ respecto, véase por ejemplo CEREZO, A. y DÍAZ, D., "El enfermo mental en el medio penitenciario español", cit., p. 3. 
la hora de asumir pacientes (excarcelados) residentes dentro de su ámbito territorial, oponiendo entre otras excusas la falta de instituciones de larga o media estancia adecuadas para estos enfermos. Esta situación pervierte el sistema a través de una doble vía: por un lado, permanecen en los hospitales psiquiátricos penitenciarios personas que ya no deberían estar en ellos, porque su estado clínico y su "peligrosidad" ya no lo justifica; por otro lado, la sobreocupación crónica de estos hospitales (unida a la falta de personal especializado en su tratamiento) ha propiciado la instalación de una "cultura regimental" en su funcionamiento, opuesta a la cultura sanitaria que debería ser su esencia ${ }^{91}$.

Esa cultura regimental se ve además favorecida por ciertas previsiones legales que fueron establecidas hace años para regular el funcionamiento interno de los hospitales psiquiátricos penitenciarios conforme a principios terapéuticos $^{92}$, pero que en la actualidad han devenido inanes o incluso claramente contraproducentes: dado el objetivo teórico a cumplir por dichos establecimientos especiales, en ellos no existe el sistema de clasificación en grados ${ }^{93}$, razón por

91 "Esta cultura está propiciada por la experiencia de que no se produce ninguna derivación de los pacientes a recursos externos, por muy bien que se haga en el hospital la labor asistencial y de rehabilitación, sistemáticamente todos los enfermos agotan el tiempo de su medida de seguridad en el psiquiátrico independientemente de la evolución de su trastorno" (SECRETARÍA GENERAL DE INSTITUCIONES PENITENCIARIAS, Hospitales Psiquiátricos dependientes de la Administración Penitenciaria. Propuesta de Acción, cit., pp. 17-18).

92 De acuerdo con lo dispuesto en el art. 264.4 RP, en los hospitales psiquiátricos penitenciarios "sólo existirán el Consejo de Dirección, cuya composición se determinará por las normas de desarrollo de este Reglamento, la Junta Económico-Administrativa y los Equipos multidisciplinares necesarios". Sobre las significativas diferencias orgánico-estructurales que existen entre los hospitales psiquiátricos penitenciarios y los centros de cumplimiento ordinario, véase CEREZO, A. y DÍAZ, D., "El enfermo mental en el medio penitenciario español", cit., pp. 7-8.

93 ZABALA BAÑOS, C., Prevalencia de trastornos mentales en prisión: Análisis de la relación con delitos y reincidencia, cit., p. 51 . 
la cual no se previó la creación dentro de su organigrama de una Junta de Tratamiento ${ }^{94}$; de forma paralela, y habida cuenta de que el art. 188.4 RP veta expresamente la posibilidad de aplicar a los internados en estas instituciones el régimen disciplinario dispuesto para los centros de cumplimiento ordinario, los hospitales psiquiátricos penitenciarios no disponen tampoco de una Comisión Disciplinaria, lo que trata de solventarse en la práctica haciendo un uso de los otros medios previstos en dicho precepto (las restricciones a la libertad personal del paciente ${ }^{95}$ y los medios coercitivos ${ }^{96}$ ) ciertamente cuestionable.

Ese es el calificativo más suave que puede desprenderse del informe remitido por el Defensor del Pueblo a la Secretaría General de Instituciones Penitenciarias tras realizar una visita en diciembre de 2018 al Hospital Psiquiátrico Penitenciario de Sevilla; en las conclusiones de dicho informe se señalaban, entre otras carencias ${ }^{97}$, las siguientes: el protocolo de contención mecánica del centro "indica que, si no existe

94 Esta absurda e insostenible situación fue solventada al menos formalmente por la Dirección General de Instituciones Penitenciarias, al incluir en la Circular 7/1996, de 12 de junio, la asignación de las funciones propias de la Junta de Tratamiento al Consejo de Dirección de los hospitales psiquiátricos penitenciarios.

95 Que teóricamente deben limitarse a las que "sean necesarias en función del estado de salud de aquél o del éxito del tratamiento” (art. 188.2 RP)

96 Cuyo empleo debería ser "una medida excepcional, que sólo podrá ser admitida por indicación del facultativo y durante el tiempo mínimo imprescindible previo al efecto del tratamiento farmacológico que esté indicado, debiéndose respetar, en todo momento, la dignidad de la persona. Incluso en los supuestos de que médicamente se considere que no hay alternativa alguna a la aplicación de los medios expresados, la medida debe ser puntualmente puesta en conocimiento de la Autoridad judicial de la que dependa el paciente, dándose traslado documental de su prescripción médica" (art. 188.3 RP).

97 Como la no adaptación de la estructura del establecimiento a los requerimientos de un centro sanitario, la falta de limpieza de sus instalaciones, o la ausencia de formación específica de los funcionarios que en ellas trabajan sobre las peculiaridades de los enfermos allí internados. 
indicación contraria, el paciente se colocará en decúbito prono en la cama" (cuando debiera ser en decúbito supino y con elevación discreta de la cabeza, por razones tanto médicas -minimizar riesgos de disfunción respiratoria o aspiración en caso de vómitos- como de dignidad y buen trato al inmovilizado); "las contenciones se aplican por períodos de tiempo muy prolongados", a pesar de que "las sujeciones mecánicas deben aplicarse con carácter excepcional, "cuando no exista otra manera menos gravosa para conseguir la finalidad perseguida", y por el tiempo imprescindible; "las aplicaciones de medios coercitivos no se comunican inmediatamente al Juez de Vigilancia Penitenciaria" (a pesar de lo dispuesto en el art. 72.3 RP); "ante una transgresión de las normas del centro, se impone una restricción a la libertad personal, prevista en el artículo 188 del Reglamento Penitenciario. Al no ser de aplicación el régimen disciplinario ordinario, los pacientes no cuentan con las garantías previstas en materia de alegaciones y recursos"; "el centro no cuenta con libro de registro para quejas y denuncias de internos relativas a actuaciones incorrectas o malos tratos por parte de los funcionarios" $"$.

\subsection{La persona con TMG declarada culpable}

Uno de los motivos por los que un individuo aquejado de TMG puede acabar, como consecuencia su enjuiciamiento, en un centro penitenciario ordinario (esto es, un centro de cumplimiento destinado en teoría exclusivamente a individuos declarados culpables) es que el órgano juzgador estime que la enfermedad mental, diagnosticada antes o durante el

98 La visita se llevó a cabo por dos técnicos del Mecanismo Nacional de Prevención de la Tortura (MNP) y un técnico del Área de Seguridad y Justicia del Defensor del Pueblo, acompañados por una Vocal del Consejo Asesor del MNP y dos técnicos externos (médico forense y psiquiatra). Las conclusiones obtenidas y las respuestas que han ido dando las diferentes administraciones públicas implicadas pueden verse en la ficha de seguimiento de la visita, que está disponible en el siguiente enlace: https://mapamnp.defensordelpueblo.es/\%2faccesibilidad\%2f582020114 0resumen.XML. 
proceso penal, no anuló completamente su capacidad de culpabilidad $^{99}$. A partir de esa conclusión, la decisión judicial puede tomar tres vías distintas: a) declarar la semi-imputabilidad del acusado (lo que conllevaría la aplicación de la eximente incompleta del art. $21.1 \mathrm{CP}$ y, en su caso, del sistema vicarial ${ }^{100}$ previsto en el art. $104 \mathrm{CP}$ ); b) estimar que el TMG solo influyó de forma leve en su conducta ilícita (lo que permitiría tenerlo en consideración en la individualización de la pena, como atenuante analógica, pero no imponer una medida de seguridad); y c) considerar que el TMG es completamente irrelevante a la hora de determinar la condena.

\subsubsection{El TMG como supuesto de semi-imputabilidad}

De las 105 resoluciones judiciales analizadas, 18 declaran que el TMG diagnosticado (perteneciente al espectro de la esquizofrenia en 11 supuestos) mermó considerablemente, pero no anuló, la capacidad de culpabilidad del acusado, razón por la cual aplican la eximente incompleta del art. 21.1 CP.

A la vista de las resoluciones analizadas, parece que el elemento fundamental a la hora de establecer la frontera entre la inimputabilidad y semi-imputabilidad debida a TMG es el factor causal-cronológico ${ }^{101}$, en cuya virtud los órganos judiciales suelen exigir una prueba fehaciente e inequívoca de que el acusado realizó los hechos que son objeto de enjuiciamiento

99 Naturalmente, el otro factor que puede dar lugar al ingreso de la persona con TMG en un centro penitenciario es que su enfermedad mental pase desapercibida durante todo el proceso penal.

100 Cfr. URRUELA MORA, A., Las medidas de seguridad y la reinserción social en la actualidad, cit., pp. 215 y ss.

101 Sobre las dificultades que suscita desde el punto de vista psiquiátricoforense la prueba de la causalidad entre un acto delictivo y el trastorno de quien lo comete, véase por ejemplo VILLAREJO RAMOS, A., "El criterio de causalidad en la valoración de la imputabilidad de los trastornos de la personalidad", Cuadernos de Medicina Forense, n 33, 2003, pp. 25 y ss. 
bajo los efectos de un brote psicótico, afirmación tajante que en muy pocos casos pueden dar los peritos (en algunos supuestos, porque pueden pasar varios días desde el suceso hasta que el investigado es explorado por un psiquiatra; en otros, probablemente porque los encargados de realizar tal pericia prefieren no arriesgarse a emitir un diagnóstico taxativo aplicable al día y hora de comisión de los hechos).

Al respecto, resulta ilustrativo el caso analizado por el ATS 861/2016, de 5 de mayo, el cual rechaza la admisión del recurso de casación presentado contra la SAP de Barcelona 727/2015, de 30 de septiembre, que enjuició al acusado, diagnosticado de esquizofrenia paranoide, de propinar un puñetazo a su madre y apuñalar dos veces con una navaja a su padre durante un almuerzo en el domicilio familiar. De acuerdo con el relato fáctico declarado probado, tales hechos sucedieron a las 14:30 h. del día 8 de noviembre de 2014, momento en el que el acusado "no estaba siguiendo el tratamiento necesario desde hacía al menos 3 o 4 semanas para la patología de esquizofrenia paranoide que padece y que le fue diagnosticada en 1998, enfermedad por la que ha sufrido 5 ingresos psiquiátricos, el último de ellos en la unidad de subagudos del Hospital Psiquiátrico de S. B. desde el 15 de enero de 2014 al 22 de agosto de 2014, del que fue dado de alta con tratamiento que abandona a partir del 26 de agosto, última visita de seguimiento a la que acudió". En su declaración, el acusado dijo que no recordaba haber agredido a sus progenitores, "a quienes en ningún momento reconoció como tal, sino que identificó como aquellas personas del servicio doméstico que trataban de envenenarlo mediante las diferentes comidas diarias". Tras practicarse su detención, la médico forense (sin especialidad en Psiquiatría) descartó la presencia de sintomatología, razón por la cual ingresó como preventivo el día 9 de noviembre de 2014, donde fue inmediatamente medicado con antipsicóticos, "necesitando en mayo de 2015 de ingreso en la unidad psiquiátrica del centro penitenciario de Brians 1". La médico psiquiatra que lo trató en dicha 
unidad informó al Tribunal sentenciador de que "se trataba de un paciente muy grave, diagnosticado de esquizofrenia paranoide con período de evolución de casi 20 años, con nula conciencia de la enfermedad y por tanto de la necesidad de tratamiento, con ideas delirantes respecto de los padres, a los que no considera como tal, estando en la creencia de que no es su hijo, que ellos forman parte del personal doméstico (cocinera la madre y chófer y jardinero el padre) que tratan de envenenarlo con las comidas para hacerse con su patrimonio y capital". A pesar de ello, la Sentencia de instancia condenó al acusado por tentativa de homicidio y lesiones en el ámbito doméstico, concurriendo la agravante de parentesco en el primero y la eximente incompleta del art. 21.1 CP en ambos supuestos, a un total de cuatro años, cuatro meses y quince días de prisión y prohibición de aproximación a las víctimas. La apreciación de la eximente incompleta en el presente caso le parece al Tribunal Supremo plenamente ajustada a Derecho, pues "no ha quedado probado fehacientemente que cometiera los hechos mientras estaba bajo un brote psicótico que hubiera anulado completamente sus facultades intelectivas y volitivas tal como exigiría la apreciación de la eximente completa" ${ }^{102}$.

102 En esta misma línea, véase ATS 779/2015, de 28 de mayo: "La Sala de instancia consideró que el padecimiento psíquico del acusado constituía base para la apreciación de la eximente incompleta de alteración o anomalía psíquica. Sobre la petición de que se apreciase la eximente como completa, el Tribunal advertía que no constaba que los hechos se produjeran durante un brote agudo de esquizofrenia, que no aparecía en los informes y que no fue apreciado por los forenses, pese a que se admitió como hipótesis la posible total anulación de la conciencia de la ilicitud del hecho"; ATS 797/2015, de 28 de mayo: "el informe del Servicio de salud concluye que el acusado tiene un diagnóstico de esquizofrenia paranoide. Su primer brote psicótico es recogido en mayo de 2012 -los hechos juzgados son a finales de dicho mes-; los médicos confirman la actividad psicótica y le remiten al programa de tratamiento multidisciplinar para primeros episodios de psicosis. Como se produce una mala evolución, en julio es remitido para tratamiento a la Unidad de Tratamiento Intensivo de Psicosis de B. La Sala partiendo de dicho informe, tomando en consideración la ingesta, en el momento de los 
En las resoluciones que declaran la semi-imputabilidad del individuo diagnosticado con TMG, el proceso de determinación de la peligrosidad del acusado pasa a un segundo plano (o simplemente se obvia) en un buen número de casos, quizá porque los hechos que motivan la condena suelen ser de una gravedad menor a los que suscitan la aplicación de la eximente completa del art. 20.1 CP. Es más: la imposición conjunta de una pena de prisión y una medida de seguridad de internamiento, conforme a lo permitido por el sistema vicarial (art. $104 \mathrm{CP}$ ), solo se acordó expresamente en tres de los supuestos analizados, en los que fueron enjuiciadas tres personas con diagnóstico de esquizofrenia por hechos calificables, respectivamente, de tentativa de asesinato ${ }^{103}$, asesinato

hechos, de alcohol y la medicación de su enfermedad, entiende que se pudo producir una interferencia nociva del alcohol junto al decurso de la enfermedad y la medicación. Partiendo de dichos extremos la Sala de forma racional apreció la eximente incompleta del artículo 21.1 en relación con el artículo 20.1 del Código Penal”.

103 ATS 688/2019, de 13 de junio. En este caso el acusado estaba "diagnosticado de esquizofrenia con predominio en los últimos años de síntomas negativos (abulia, apatía) asociados a escasa introspección y alteraciones de conducta reiteradas dentro y fuera del ámbito familiar. Inició tratamiento ambulatorio en el centro de salud mental de M. E. en 1984, con ingresos en el hospital general de V., en la unidad de psiquiatría de un hospital alemán, en el hospital psiquiátrico de V., en el hospital S. de M. -unidad de psiquiatría del antiguo hospital provincial-, en el complejo asistencial S. S., en el hospital S. J., en vivienda supervisada en P., en unidad de rehabilitación del hospital S. T., y un total de 43 ingresos en la unidad de hospitalización psiquiátrica en distintos centros hospitalarios de B. El acusado fue asistido en el centro de salud de M. el 20 de octubre de 2016 a las 09:44 horas, por esquizofrenia paranoide (negando alucinaciones). En el momento de la exploración por el médico forense, el 20 de octubre de 2016 a las 14:20 horas, no se observó agitación, ni alteraciones del estado de ánimo ni alucinaciones, pero sí ideación delirante de perjuicio centrada en la figura de su padre con el que, al parecer, tiene una relación caracterizada por la conflictividad y los enfrentamientos frecuentes. Él atribuía su enfermedad a su padre y le responsabiliza de los múltiples ingresos hospitalarios que ha requerido a lo largo de su vida. Así como manifestó haber abandonado la medicación antipsicótica hace 3 semanas y no haber consumido tóxicos recientemente". 
consumado ${ }^{104}$ y detención ilegal, malos tratos, agresión sexual y delito leve de daños ${ }^{105}$. En este contexto, llama poderosamente la atención la STS 158/2015, de 17 de marzo, la cual, a pesar de anular la resolución recurrida para confirmar el veredicto del Jurado, favorable a la apreciación de una eximente incompleta por trastorno de la personalidad grave, dicta segunda sentencia condenando al acusado de asesinato y aborto exclusivamente al cumplimiento de una pena de 16 años de prisión, sin plantearse siquiera la conveniencia o oportunidad de aplicar al trastornado una medida de seguridad.

En cualquier caso, lo que se deduce claramente de la letra de la ley es que al interno declarado semi-imputable por su TMG al que se le ha impuesto una pena y una medida de seguridad privativas de libertad, debe iniciar la ejecución de su sentencia cumpliendo en primer lugar la medida, cumplimiento que deberá abonarse posteriormente para el de la pena, la cual además podrá suspenderse si con su ejecución se pusieran en peligro los efectos conseguidos a través de aquélla (art. 99 CP). Conforme a lo dispuesto en el art. 183 RP, los establecimientos o unidades psiquiátricas penitenciarias son los únicos centros especiales de la red carcelaria destinados al

104 STS 271/2018, de 6 de junio: "La sentencia del Tribunal Jurado declaró probado que «el acusado al tiempo de cometer los hechos padecía una esquizofrenia hebefrénica, lo que unido al consumo de alcohol, cannabis y benzodiacepinas le provocó un estado que afectó de manera grave y significativa a sus capacidades intelectivas y volitivas, sin llegar a anular completa y absolutamente tales capacidades». En este caso el Tribunal de apelación confirmó las conclusiones probatorias del Jurado que no apreció alteración o trastorno de tal entidad susceptible de suministrar base fáctica para la circunstancia de exención ahora demandada. Lo hizo a partir de la pericial forense y de los múltiples informes que se vertieron en el juicio oral por los peritos, que descartaron que el acusado actuara bajo un brote psicótico que le impidiera ser consciente del acto criminal que estaba cometiendo, todo ello en relación con la propia dinámica de los hechos, incluido su esfuerzo por tratar de eliminar rastros".

105 ATS 707/2017, de 20 de abril. El acusado en esta causa estaba diagnosticado de esquizofrenia simple (trastorno psicótico) y trastorno de la personalidad tipo límite, con rasgos antisociales. 
cumplimiento de medidas de seguridad privativas de libertad aplicadas a sujetos con TMG por los Tribunales, de modo que no existe ninguna previsión legal que permita el cumplimiento de una medida de seguridad de internamiento por parte de estos sujetos en un centro penitenciario ordinario ${ }^{106}$.

Sin embargo, la realidad que se vislumbra a partir de los datos oficiales ofrecidos por Instituciones Penitenciarias choca frontalmente con el marco legal expuesto: de acuerdo con el Anuario del Ministerio del Interior correspondiente a 2014, en ese año había en España (excluyendo a Cataluña) 529 personas cumpliendo una medida de internamiento psiquiátrico, y "si a esa cifra le restamos las 397 personas internadas en los hospitales psiquiátricos penitenciarios de Sevilla y de Alicante, se obtiene un total de 132 internos que se encuentran cumpliendo una medida de seguridad en un centro penitenciario ordinario"107. En 2018, el panorama no parece haber cambiado sustancialmente (más bien ha empeorado): según los datos oficiales de la misma fuente, en el ámbito competencial de la Administración General del Estado (lo que excluye a Cataluña), había 531 reclusos cumpliendo una medida de seguridad de internamiento, de los que 425 se hallaban ingresados en los hospitales psiquiátricos de Alicante y Sevilla (junto a otros 33 internos, que se encontraban como penados o preventivos); la conclusión es evidente: 109 personas estaban cumpliendo una medida de seguridad en centros penitenciarios ordinarios ${ }^{108}$,

106 Y ello a pesar de la confusa redacción de la Instrucción 19/2011, de 16 de noviembre, del Director General de Coordinación Territorial y Medio Abierto de la Secretaría General de Instituciones Penitenciarias, sobre el cumplimiento de las medidas de seguridad competencia de la Administración Penitenciaria.

107 CEREZO, A. y DÍAZ, D., "El enfermo mental en el medio penitenciario español", cit., p. 12.

108 Anuario Estadístico del Ministerio del Interior 2018, Madrid, Secretaría General Técnica, julio de 2019, pp. 316-320. Disponible en: http:// www.interior.gob.es/documents/642317/1204854/Anuario+Estad $\%$ C3\%ADstico+del+Ministerio+del+Interior+2018/5a35fad7-5386-44fb-83a e-9b14e678cc4a 
sin que parezca que hubiera otro motivo que lo justificara distinto al hecho de que, lisa y llanamente, no había plazas disponibles en los establecimientos psiquiátricos penitenciarios.

Esta situación de absoluta y flagrante ilegalidad coloca además a los internos declarados semi-imputables en unas condiciones de cumplimiento más gravosas que las del resto de recluidos "normales": no pueden disfrutar de los beneficios penitenciarios propios del sistema de individualización científica mientras se encuentran cumpliendo la medida de seguridad (pues durante este periodo no tienen la consideración de "penados" y por tanto se suspende su clasificación en grado de tratamiento) ${ }^{109}$. Si se quiere tener una visión completa del panorama, añádase a lo anterior algunos datos ya mencionados: la inexistencia de salas o módulos específicos en los centros de cumplimiento ordinario destinados a estas personas, el reducido número de plazas en las enfermerías con las que cuentan dichos centros para alojarlos (recuérdese, según el Gobierno de la Nación solo el 16\% de los internos con TMG residen preferentemente en ellas) y la total ausencia de servicios psiquiátricos propios que se constata en buena parte de nuestra red penitenciaria.

\subsubsection{El TMG como circunstancia atenuante}

28 resoluciones judiciales (entre las que se incluyen 19 casos de trastornos psicóticos o del espectro de la esquizofrenia) de las 105 analizadas concluyen que el trastorno mental de la persona enjuiciada solo puede estimarse como circunstancia atenuante por analogía, conforme a lo dispuesto en el art. 21.7 CP.

Atendiendo a la jurisprudencia establecida con carácter general por la Sala de lo Penal del Tribunal Supremo en relación con las esquizofrenias (a la que ya se ha hecho referencia con anterioridad), parecería lógico esperar que la

109 En este mismo sentido, CEREZO, A. y DÍAZ, D., "El enfermo mental en el medio penitenciario español", cit., pp. 18-19. 
atenuante analógica resultara aplicable por la mera constatación del TMG o sus "residuos", sin que en tales supuestos se requiera ni la comprobación de la existencia de un brote psicótico en el momento de comisión de los hechos (pues en tales casos debería apreciarse la eximente completa), ni evidencias de que el acusado se comportara en dicho momento de forma "anómala" (supuestos en los que resultaría de aplicación la eximente incompleta).

El examen de buena parte de las resoluciones que han sido objeto de estudio obligan, sin embargo, a llegar a otra conclusión ${ }^{110}$. De hecho, en varios supuestos la parte del

$110 \mathrm{La}$ ausencia de prueba sobre la concurrencia de un brote psicótico en el momento de comisión de los hechos motiva el descarte de la eximente incompleta y la aplicación de la atenuante analógica, por ejemplo, en los siguientes casos: ATS 287/2015, de 5 de febrero: "la Sala de instancia no fue ajena a los padecimientos psicológicos de Octavio. Pese a no acreditarse que, en el momento de los hechos, se encontrase en un episodio psicótico, estimó concurrente la circunstancia atenuante analógica del artículo $21.7^{\circ}$ en relación con los artículos $21.1^{\circ}$ y $20.2^{\circ}$ del Código Penal"; ATS 189/2015, de 19 de febrero: la disminución de las capacidades del acusado era leve, "puesto que no actuó bajo una descompensación psicótica de la esquizofrenia que padece"; ATS 914/2015, de 3 de junio: "En la exploración que le realizaron los médicos forenses apreciaron que se encontraba estabilizado en la fecha de los hechos, y ese mismo día fue reconocido en un centro médico, en el que le suministraron "Trankimazin' porque tenía ansiedad, sin constatar ningún brote psicótico"; ATS 441/2016, de 17 de marzo: el acusado "había recibido tratamiento psiquiátrico en fechas no determinadas por un trastorno de ansiedad. Días después, se le diagnosticó un trastorno psicótico paranoide (...). No acepta la Sala de instancia que en el momento de comisión de los hechos el inculpado estuviera bajo un brote psicótico agudo"; ATS 221/2017, de 29 de marzo: "la perito informante compareció en el acto del plenario e indicó que el trastorno psicótico del acusado venía inducido por el consumo de sustancias estupefacientes, por lo que podría reproducirse dependiendo de sus hábitos de consumo, pero que no había constancia en el Instituto de medicina legal de que en el momento de la comisión de los hechos objeto de enjuiciamiento, el acusado pudiera encontrarse afectado por la patología mencionada"; STS 440/2018, de 4 de octubre: "la negación de hechos por parte del acusado, y la indeterminación del momento temporal de realización de los hechos por los que ha sido enjuiciado, impiden conocer las concretas circunstancias que concurrieron 
relato fáctico que se refiere al TMG padecido por el acusado se diferencia, en poco o en nada, del declarado probado en otros casos en los que se apreció la concurrencia de la eximente incompleta, y sin embargo el órgano judicial se resiste a declarar la semi-imputabilidad del acusado. Así por ejemplo, la STS 694/2017, de 24 de octubre, a pesar de declarar probado que en la fecha de los hechos enjuiciados "el acusado se encontraba en tratamiento de deshabituación de las drogas tomando metadona por su cuenta, así como que estaba diagnosticado de esquizofrenia paranoide crónica, circunstancia que combinada con su toxicomanía condujo al reconocimiento en febrero de 2015 , de un $83 \%$ de discapacidad por el Departamento correspondiente de la Generalitat de Cataluña", concluye que lo procedente es aplicar la atenuante analógica como muy cualificada, dado que "no contamos con un informe específico sobre su situación en el momento de autos, que impide la estimación de una eximente incompleta por afectación grave"; y ello a pesar de estimar que circunstancias tales como la esquizofrenia paranoide crónica padecida por el enjuiciado, su comportamiento durante los hechos (al ser sorprendido saltó una valla de seis u ocho metros de altura), y la discapacidad en un $83 \%$ que le fue reconocida (una vez le fue amputada la pierna), determinan "una base biopatológica" de la que se infiere que la afectación se presentó "con mayor intensidad que la simplemente determinada por la politoxicomanía de larga trayectoria en relación a la comisión del delito cometido contra la propiedad".

En otras ocasiones, las conclusiones emitidas en el juicio por el médico forense, negando la relevancia del trastorno mental en la capacidad de culpabilidad del acusado, son asumidas por el juzgador de forma acrítica e incuestionada, a

en él en el momento de cometer los hechos y menos aún que las dos muertes de las que aparece como autor hayan sido ejecutados bajo los efectos de un brote esquizofrénico". 
pesar de que dichas afirmaciones puedan generar dudas más que razonables atendiendo a su historial clínico. En este contexto, destaca el caso analizado en primera instancia por la SAN 29/2016, de 21 de septiembre, que condenó al acusado de publicar tuits ensalzando a ETA entre abril de 2012 y noviembre de 2013 como autor de un delito de enaltecimiento del terrorismo sin la concurrencia de circunstancias modificativas de la responsabilidad penal, y ello a pesar de reconocer en los hechos probados que tal acusado, "quien desde el año 1998 ha seguido diversos tratamientos psiquiátricos acordes a los variados diagnósticos de su sintomatología, padece un síndrome delirante sensitivo de referencia con un trastorno paranoide de la personalidad"; para fundamentar su decisión, la Audiencia Nacional tomaba como base fundamental el informe emitido por la médico forense el 15 de febrero de 2015, en el que si bien recogía el larguísimo historial psiquiátrico del enjuiciado (lo que incluía diversos diagnósticos -varios de ellos coincidentes con la época en la que publicó los mensajes- con síndromes o ideas delirantes, sintomatología que es calificada en el propio informe "de rango psicótico"), concluía sin embargo que la existencia de tales trastornos "no altera el contenido del pensamiento, de manera que conoce la realidad y puede comportarse acorde con dicho conocimiento máxime cuando su conducta se extiende en el tiempo y carece de relación con su delirio sensitivo". La forma de proceder del Tribunal de instancia (al motivar su fallo únicamente en la conclusión final del informe pericial, obviando las dudas que se desprenden del resto de su contenido en torno a la capacidad de culpabilidad del acusado) fue plenamente legitimada por la decisión mayoritaria adoptada en la STS 335/2017, de 11 de mayo ${ }^{111}$, pero duramente criticada

$111 \mathrm{La}$ Sentencia considera que la conclusión alcanzada por la Audiencia Nacional en torno a la irrelevancia de los trastornos del acusado en su culpabilidad es "razonada, fundada y razonable", dado que tenía "firme apoyatura en un informe forense". Según la decisión mayoritaria, "sería imprudente discrepar del único dictamen pericial. El Juez es peritus 
por los dos votos particulares que se recogen en la misma Sentencia de casación ${ }^{112}$.

Huelga decir que la diferenciación entre lo que constituye una eximente incompleta y lo que debe apreciarse como una circunstancia atenuante no es desde luego una cuestión baladí, toda vez que, como ya se ha señalado, la primera permite la aplicación del sistema vicarial (lo que a su vez posibilita, al menos teóricamente, que el condenado afectado por TMG reciba un tratamiento en forma de medida de seguridad antes de comenzar a cumplir la pena correspondiente, la cual además podrá ser suspendida si pusiera en riesgo los logros obtenidos con dicho tratamiento). En cambio, las consecuencias que en la práctica tiene la aplicación de la atenuante se limitan, en el mejor de los casos, a acortar de algún modo el máximo de pena a imponer al condenado, de forma

peritorum, pero no omnisciente (...). No hay pues la más mínima base para tener dudas de que al tiempo de cometer la infracción penal, a causa de cualquier anomalía o alteración psíquica, el recurrente no estuviese en condiciones de comprender la ilicitud del hecho o actuar conforme a esa comprensión”. A pesar de ello, el Tribunal Supremo estima parcialmente el recurso de casación para apreciar la concurrencia de la atenuante analógica del art. 21.7 CP, en relación con los arts. 20.1 y $21.1 \mathrm{CP}$.

112 Véase al respecto el interesantísimo contenido de los votos particulares pronunciados por los magistrados Luciano Valera y Joaquín Giménez, en los que, entre otras cosas, se cuestiona: la asunción por el Tribunal de instancia de una conclusión pericial emitida en una fecha en la que el acusado aún está "pendiente de valoración por el servicio de psiquiatría de zona", desconectada de los antecedentes psiquiátricos del acusado y carente de fijación cronológica del cuadro sintomatológico; la omisión en la fundamentación de la sentencia de los términos "psicosis" y "tratamiento antipsicótico" (presentes en el informe de la forense), y la aceptación pasiva y acrítica por parte de la Sala juzgadora de un informe pericial deficiente, lo que constituye "un verdadero salto en el vacío". Conforme a ello, el primer voto particular estima que debió declarase la nulidad de la sentencia recurrida (exigiendo otra que motivase más adecuada y sustancialmente el juicio de imputabilidad) y el segundo voto considera que debió haberse estimado el recurso, en el sentido de apreciar la concurrencia de la eximente completa del art. 20.1 CP. 
que el "destino penitenciario" de estos internos parece, cuando menos, incierto: si la enfermedad se agrava lo suficiente durante el tiempo de cumplimiento de su condena quizá puedan optar a la declaración de trastorno mental sobrevenido, siempre que el Juez de Vigilancia Penitenciaria estime que se dan los requisitos establecidos a tal efecto en el art. $60 \mathrm{CP}$; de no ser así, el recluso con TMG deberá contentarse con su posible inclusión en el PAIEM, pero en todo caso permanecerá en el centro penitenciario de cumplimiento.

\subsubsection{El TMG considerado penalmente irrelevante}

48 de las 105 resoluciones judiciales analizadas concluyen que el trastorno mental del acusado (entre los que se incluyen 17 casos con síntomas psicóticos o trastornos del espectro de la esquizofrenia) no afectó de ningún modo a su culpabilidad, razón por la cual no es tenido en cuenta en la determinación de la condena.

Las mismas "posibilidades penitenciarias" que se acaban de exponer a propósito de los condenados por TMG con aplicación de la atenuante analógica son las que tienen los individuos cuyo trastorno ha sido declarado irrelevante en su sentencia condenatoria, por considerar que la enfermedad mental diagnosticada no afectó en modo alguno a la comisión de los hechos que se les imputan. Irrelevancia que, nuevamente, en ocasiones parece chocar frontalmente con lo que se supone es doctrina jurisprudencial consolidada en relación con la afectación de las psicosis o esquizofrenias a la capacidad de culpabilidad; así por ejemplo, se descarta la trascendencia de un trastorno esquizoide con brotes o descompensaciones porque "es harto dudoso que en el dilatado lapso temporal durante el que realizó la referida conducta se encontrara en fases de tal carácter" (STS 628/2017, de 21 de septiembre); o la de una esquizofrenia paranoide "residual", porque esta "implica no estar bajo síntomas delirantes o paranoides activos" (ATS 361/2018, de 18 de enero). 
Idéntico destino corren aquellas personas cuyo TMG no fue objeto de valoración por parte del Tribunal, al ignorar la defensa durante el proceso penal la existencia de pruebas indicativas de dicho trastorno ${ }^{113}$; pruebas cuya alegación posterior, por lo demás, no justifica en opinión del Tribunal Supremo la interposición de un recurso de revisión ${ }^{114}$, por más que la sentencia condenatoria fuera dictada con la conformidad del acusado ${ }^{115}$.

113 Así por ejemplo, el ATS 8076/2016, de 5 de septiembre rechaza la interposición del recurso de revisión en base a documentación probatoria del trastorno de esquizofrenia paranoide del condenado (la cual acredita entre otras cosas numeroso ingresos hospitalarios debido a dicho trastorno y el reconocimiento de un grado de discapacidad global del 65\%), circunstancias todas ellas que no fueron conocidas por su defensa hasta finalizada la causa. Frente a lo alegado, afirma el Tribunal Supremo que "de los documentos aportados no resultan elementos suficientes para entender que en el momento de los hechos, que tuvieron lugar el 18 de junio de 2014, el autor se encontrara bajo los efectos perturbadores de la mencionada alteración mental que le fue apreciada en los años 2005 y 2006. Tampoco de los hechos resultan indicios de que esa afectación existiera en ese momento. Y, finalmente, no parece razonable que una alteración como la mencionada pudiera pasar desapercibida para todos los que tuvieron contacto con el promovente, salvo que estuviera suficientemente controlada, en cuyo caso, no causaría efectos en las capacidades del sujeto para comprender la ilicitud del hecho o para actuar conforme a esa comprensión".

114 Conforme a lo dispuesto en el art. 954.1.d) LECR, en cuya virtud "se podrá solicitar la revisión de las sentencias firmes (...) d) Cuando después de la sentencia sobrevenga el conocimiento de hechos o elementos de prueba, que, de haber sido aportados, hubieran determinado la absolución o una condena menos grave".

115 En este sentido, véase por ejemplo ATS 12620/2017, de 11 de diciembre: "el diagnóstico de la enfermedad y sus dictámenes médicos pudieron ser aportados en el plenario y el expediente de incapacitación parcial no evidencia la inocencia de unos hechos cometidos cinco años antes, pero es que además no podría ahora concretarse que en el momento de los hechos tuviera afectadas sus facultades. (...) el alcance de la capacidad de $\mathrm{H}$. en el proceso y en relación a las infracciones, fue expresamente objeto de pronunciamiento por parte del Juez de lo Penal, quien dictó sentencia que validó la expresa conformidad del acusado y su defensa con las calificaciones formuladas por el Ministerio Fiscal en el sentido de estimar los hechos constitutivos de conducción temeraria con la 
Al respecto, causa cierto sonrojo el ATS 1757/2016, de 26 de febrero, cuando afirma que la declaración judicial de incapacidad total y absoluta del acusado para regir su persona y bienes, previa a su condena e ignorada al tiempo de dictarse sentencia por conformidad, resulta irrelevante a efectos de cuestionar la validez del consentimiento emitido por el condenado, pues dicha incapacidad "tendrá el alcance y extensión que regula el Código Civil”, y su declaración "no es trasvasable miméticamente a los efectos penales y, tampoco, al proceso penal". En este sentido, el Tribunal estima que lo establecido en el art. $25 \mathrm{CP}$ (el cual, tras su reforma operada por LO 1/2015, entiende por persona con discapacidad la que "requiera de asistencia o apoyo para el ejercicio de su capacidad jurídica y para la toma de decisiones respecto de su persona" ${ }^{\text {"116) }}$ resulta igualmente irrelevante, pues "los conceptos que maneja el art. $25 \mathrm{CP}$ no lo son a los efectos que pretende el solicitante sino para tenerlos en cuenta en la aplicación de preceptos de la parte especial que tenga por sujeto pasivo o perjudicado a un incapaz o discapacitado". Dado que en

circunstancia atenuante de dilaciones indebidas muy cualificadas y de un delito de lesiones, consideró la calificación de los hechos correcta y la pena solicitada procedente, por lo que dictó sentencia acorde con la conformidad de las partes; ATS 5768/2020, de 24 de julio: la solicitud "no se apoya en datos nuevos antes ignorados, sino en alegar que padece una esquizofrenia paranoide, también en el momento de los hechos, y que estaba en tratamiento no pudiendo aportar documentación al efecto, aunque la sentencia se dictó de conformidad y en el fundamento de derecho segundo se recoge que la solicitante alegó hallarse en tratamiento psiquiátrico sin aportar prueba que lo acreditase. (...) Por lo demás, conviene subrayar que la participación de la penada en el delito de atentado, delito leve de daños y delito leve de lesiones, se apoya en el reconocimiento de la acusada de su intervención en los hechos probados, que se reflejan en la sentencia".

116 Según el Preámbulo de la LO 1/2015, dicha modificación se lleva a cabo para adecuar las normas penales "a la Convención Internacional sobre los Derechos de las Personas con Discapacidad, hecha en Nueva York el 13 de diciembre de 2006, que pretende prevenir las conductas discriminatorias que puedan impedirles el disfrute de sus derechos en igualdad de condiciones". 
el procedimiento penal ya constaba el trastorno mental del acusado (aunque no su declaración judicial de incapacidad total y absoluta), "sin que el Juez de instrucción, el Fiscal o su propio abogado advirtieran la concurrencia de algunos de los supuestos previstos en el art. 381 a 383 LECR (...), en dicho procedimiento penal no cabe afirmar que el acusado carezca de la capacidad de prestar conformidad pues no existe prueba que así lo determine. Por tanto, su capacidad procesal permanece intacta. $\mathrm{Y}$ así es como tiene lugar la conformidad que presta el acusado sin que el Juez de lo Penal, el Fiscal o su abogado hayan entendido, no existía base probatoria para ello, que el acusado no estaba capacitado para prestar la conformidad que expresó. La deficiencia mental que se le detectó, no era inhabilitante para la conformidad procesal, tuvo su expresión legal en la afirmación de una atenuante. Debe añadirse que, en el proceso penal, no existe la posibilidad de que el tutor pueda conformarse con el delito y pena que se impone al acusado por muy incapacitado civilmente que estuviera éste".

\section{Algunas conclusiones}

Quizá resulte exagerado afirmar que los centros penitenciarios españoles (los ordinarios y los psiquiátricos) están cumpliendo actualmente las mismas funciones que hace un siglo se encomendaban a los manicomios, pero el análisis de la situación actual de las personas con TMG que se hallan internadas en el sistema carcelario no permite, desde luego, mantener una visión optimista de dicha problemática: la legislación penal y penitenciaria cuenta con elementos, si no idóneos, al menos suficientes para darles una respuesta adecuada, pero la aplicación que de dicha legislación realizan los órganos judiciales (conforme a unos criterios que, como mínimo, parecen excesivamente rígidos) coadyuva a mantenerlos dentro de la órbita carcelaria, durante el máximo tiempo que resulte legalmente posible, y alejados del único 
tratamiento (el asistencial comunitario) que, en opinión de los expertos, puede conseguir algo más que su mera inocuización y aislamiento.

Este modo de proceder provoca, inevitablemente, la sobresaturación de los hospitales psiquiátricos penitenciarios y la consecuente permanencia de internos con TMG diagnosticado en centros de cumplimiento ordinario, en ocasiones en virtud de una medida de seguridad de internamiento (lo que resulta a todas luces ilegal) y en otras de una pena privativa de libertad, a pesar de su diagnóstico y su eventual declaración judicial de incapacidad. En este contexto, el PAIEM, por muy positiva que haya resultado su implantación a la hora de mejorar las condiciones de internamiento de los aquejados de TMG, puede estar causando simultáneamente un efecto pernicioso: el de servir de coartada para no afrontar una problemática que debe ser abordada desde una perspectiva mucho más amplia y profunda que la estrictamente penitenciaria.

La escasez de recursos y la descoordinación de las administraciones públicas implicadas en dicha problemática perjudica a los presos con TMG de diferentes formas: a) la ausencia o insuficiencia de una red comunitaria asistencial adecuada para estas personas desincentiva a los jueces a la hora de adoptar una pena o medida de seguridad alternativas al mantenimiento en prisión o en el psiquiátrico penitenciario (algo a lo que ya de por sí no parecen demasiado proclives); b) una vez cumplida la condena, o extinguida la duración máxima del internamiento decretado, el individuo con TMG tampoco encuentra el apoyo institucional necesario para dar continuidad al tratamiento de su enfermedad, de modo que el "síndrome de las puertas giratorias" (comisión de un nuevo hecho delictivo al poco tiempo de su excarcelación, lo que se traduce en su vuelta a la prisión o psiquiátrico penitenciario) se manifiesta en muchos casos, especialmente cuando el entorno familiar del excarcelado ya no puede o no quiere hacerse cargo del cuidado de una persona que, por las características de su enfermedad, resulta muy conflictiva. 
Las soluciones a esta lamentable situación parecen obvias: incremento y mejora de los recursos (materiales y personales) destinados al tratamiento de personas con TMG, culminación del proceso de transferencia autonómica y mayor coordinación entre las redes sanitaria, de justicia y penitenciaria, son algunas de ellas; como también lo sería la puesta en funcionamiento de unidades psiquiátricas penitenciarias (cuya creación está prevista en el art. 184 del Reglamento Penitenciario desde hace casi 25 años) al menos en las macro prisiones españolas, con el fin de posibilitar el cumplimiento de lo que establece el art. 16 Ley Orgánica General Penitenciaria (aprobada por aclamación jhace más de cuarenta años!) y que, hoy por hoy, parece una utopía: "Cualquiera que sea el centro en el que tenga lugar el ingreso, se procederá, de manera inmediata, a una completa separación, teniendo en cuenta el sexo, emotividad, edad, antecedentes, estado físico y mental y, respecto de los penados, las exigencias del tratamiento. En consecuencia: (...) d) Los que presenten enfermedad o deficiencias físicas o mentales estarán separados de los que puedan seguir el régimen normal del establecimiento".

\section{Bibliografía}

AAVV, Guía de Práctica Clínica de Intervenciones Psicosociales en el Trastorno Mental Grave, Ministerio de Sanidad y Política Social/Ministerio de Ciencia e Innovación, 2009.

ALTAMIRANO ARGUDO, Z., El bienestar psicológico en prisión: Antecedentes y consecuencias, Tesis Doctoral, Universidad Autónoma de Madrid, 2013.

AMERICAN PSYCHIATRIC ASSOCIATION, Manual Diagnóstico y Estadístico de los Trastornos Mentales (DSM-5), $5^{\circ}$ ed., Madrid, Editorial Médica Panamericana, 2014.

ARENAL, C., "Ley de dementes", en Artículos sobre beneficencia y prisiones. Volumen III, Madrid, Librería de Victoriano Suárez, 1900. 
ARNAU, F., GARCÍA-GUERRERO, J., BENITO, A., VERA-REMARTÍNEZ, E. J., BAQUERO, A. y HARO, G., "Sociodemographic, Clinical, and Therapeutic Aspects of Penitentiary Psychiatric Consultation: Toward Integration into the General Mental Health Services", Journal of Forensic Sciences, Vol. 65, n 1, 2020, pp. 160-165. https://doi.org/10.1111/1556-4029.14137

ASOCIACIÓN ESPAÑOLA DE NEUROPSIQUIATRÍA (AEN), Por una atención integral a las personas con trastornos graves de salud mental basada en el respeto de sus derechos, Madrid, enero de 2009.

BARRIOS FLORES, L. F., "Un siglo de psiquiatría penitenciaria”, Revista Española de Sanidad Penitenciaria, Vol. 2, no 1, 2000, pp. 23-30.

BARRIOS FLORES, L. F., "Derecho y salud mental (logros conseguidos y retos pendientes en España). Informe SESPAS 2020", Gaceta Sanitaria, 2020, pp. 1-5.

BUCHANAN, A., SINT, K., SWANSON, J., ROSENHECK, R., "Correlates of Future Violence in People Being Treated for Schizophrenia", American Journal of Psychiatry, Vol. 176, issue 9, 2019, pp. 694-701. https://doi.org/10.1176/appi.ajp.2019.18080909

CAMPOS, R. y NOVELLA, E., , "La higiene mental durante el primer franquismo. De la higiene racial a la prevención de la enfermedad mental", Dynamis, 37 (1), 2017, pp. 65-87. http://dx.doi.org/10.4321/S021195362017000100004

CAMPOS MARÍN, R., "La psiquiatría en la ciudad. Higiene mental y asistencia extramanicomial en España en la década de 1920", Frenia, Vol. IV-1, 2004, pp. 101-111.

CAMPOS MARÍN, R. y HUERTAS GARCÍA-ALEJO, R., "Los lugares de la locura: reflexiones historiográficas en torno a los manicomios y su papel en la génesis y el desarrollo de la psiquiatría", Arbor. Ciencia, Pensamiento y Cultura, Vol. 184, n 731, 2008, pp. 471-480. 
CARBONELL MATEU, J. C., GÓMEZ COLOMER, J. L. y MENGUAL I LULL, J. B., Enfermedad mental y delito. Aspectos psiquiátricos, penales y procesales, Madrid, Civitas, 1987.

CASTEJÓN, M. A., PALLARÉS, J. y LÓPEZ, J. M., "Las personas con TMG en el ámbito penal y penitenciario. Situación actual y propuestas de intervención psicosocial”, Boletín de la Asociación Madrileña de Salud Mental, 2010, pp. 14-24.

CEREZO, A. y DÍAZ, D., "El enfermo mental en el medio penitenciario español", International E-Journal of Criminal Sciences, $\mathrm{n}^{\circ}$ 10, 2016, pp. 1-24.

CHECA GONZÁLEZ, M. J., Manual práctico de Psiquiatría Forense, Barcelona, Elsevier Masson, 2010.

CUELLO CALÓN, E., Penología. Las penas y las medidas de seguridad. Su ejecución, Madrid, Reus, 1920.

DESVIAT, M., "Los avatares de una ilusión: la reforma psiquiátrica en España”, Cuadernos de Trabajo Social, Vol. 23, 2010, pp. 253-263.

DIRECCIÓN GENERAL DE INSTITUCIONES PENITENCIARIAS, "Programa marco para la Atención Integral a Enfermos Mentales en Centros Penitenciarios", en MINISTERIO DEL INTERIOR, Estrategia Global de Actuación en Salud Mental, 2007.

DOMÈNECH, E., Introducción a la historia de la Psicopatología, Barcelona, PPU, 1991.

DUALDE BELTRÁN, F., "La profilaxis de la enfermedad mental en la psiquiatría franquista: esquizofrenia, eugenesia y consejo matrimonial", Revista de la Asociación Española de Neuropsiquiatría, 24 (92), 2004, pp. 131-161.

EQUIP VINCLES SALUT, Guía para la Promoción de la Salud Mental en el Medio Penitenciario, Madrid, Ministerio del Interior/Secretaría General de Instituciones Penitenciarias, 2011. 
FUENTES, M. y FERNÁNDEZ, E. M., "La esquizofrenia en el medio penitenciario", Revista de la Asociación Española de Neuropsiquiatría, Vol. 36, $\mathrm{n}^{\circ} 130$, 2016, pp. 405-420. https://doi.org/10.4321/S021157352016000200007

GARCÍA ARÁN, M., Fundamentos y aplicación de penas y medidas de seguridad en el Código Penal de 1995, Pamplona, Aranzadi, 1997.

HART, B., The psychology of insanity, Cambridge University Press, 1912.

JORGE BARREIRO, Agustín, "El enfermo mental delincuente y peligroso ante el CP de 1995", Revista de Derecho Penal y Criminología, $2^{\mathrm{a}}$ Época, $\mathrm{n}^{\mathrm{o}}$ 6, 2000, pp. 177-222.

LACAL CUENA, P., PEÑARANDA DEL RÍO, J. y SOLAR CALVO, P., ¿¿Debe un enfermo mental estar en prisión? Situación actual y cuestiones que plantea la STS 84/2018, de 16 de julio", Revista General de Derecho Penal, no 30, 2018, pp. 1-36.

LAMBERTI, J. S, KATSETOS, V., JACOBOWITZ, D. B. y WEISMAN, R. L., "Psychosis, Mania and Criminal Recidivism: Associations and Implications for Prevention", Harvard Review of Psychiatry, Vol. 28, issue 3, 2020, pp. 179-202. https://doi.org/10.4321/S021157352016000200007

LÓPEZ LÓPEZ, A., "El enfermo mental y la legislación penitenciaria. Psiquiatría penitenciaria, perspectiva histórica y actual", en DELGADO BUENO, S. (dir.), Tratado de Medicina Legal y Ciencias Forenses V: Psiquiatría Legal y Forense, Barcelona, Bosch, 2013, pp. 343-368.

MARÍN-BASALLOTE， N. y NAVARRO-REPISO, C., "Estudio de la prevalencia de trastorno mental grave (TMG) en los centros penitenciarios de Puerto I, II y III del Puerto de Santa María (Cádiz): nuevas estrategias en la asistencia psiquiátrica en las prisiones”, 
Revista Española de Sanidad Penitenciaria, Vol. 14, $\mathrm{n}^{\circ}$ 3, 2012, pp. 80-85.

MARTÍNEZ CORDERO, M., El penal de El Puerto de Santa María, ed. del autor, 2003.

MARTÍNEZ GARAY, L., "La incertidumbre de los pronósticos de peligrosidad: consecuencias para la dogmática de las medidas de seguridad", InDret, 2/2014, pp. 1-77. MARTÍNEZ GARAY, L.; MONTES SUAY, F., "El uso de valoraciones del riesgo de violencia en Derecho Penal: algunas cautelas necesarias", InDret, 2/2018, pp. 1-46.

MATEO AYALA, E. J., La medida de seguridad de internamiento psiquiátrico. Su ejecución y control, Madrid, Edersa, 2004.

MATEO SOLER, M., GÓMEZ DE TOJEIRO ROCE, J., ÁLVAREZ CRESPO, R., FERNÁNDEZ MODAMIO, M., BENGOECHEA IBACETA, J., FERNÁNDEZ IGLESIAS, P., GURRÍA FLORES, G., GIL SANZ, D., RÍOS MARTÍNEZ, J. y GAITE PINDADO, L., "Programa Puente Extendido. Salud mental en penas y medidas alternativas", Documentos Penitenciarios, $\mathrm{n}^{\circ} 18$ (2018), pp. 1-27.

MIR PUIG, S., Derecho Penal. Parte General, 10ª ed., Barcelona, Reppertor, 2016.

MONAHAN, J., STEADMAN, H. J., ROBBINS, P. C., APPELBAUM, P., BANKS, S., GRISSO, T., HEILBRUN, K., MULVEY, E. P., ROTH, L. y SILVER, E., "An Actuarial Model of Violence Risk Assesment for Persons With Mental Disorders", Psychiatric Services, Vol. 56, $\mathrm{n}^{\circ}$ 7, 2005, pp. 810-815.

MUÑOZ ESCANDELL, I. (coord./red.), Informe sobre el estado de los derechos humanos en salud mental 2019, Confederación SALUD MENTAL ESPAÑA, Madrid, mayo de 2020.

NARVÁEZ RODRÍGUEZ, A., "Las medidas de seguridad", Estudios Jurídicos del Ministerio Fiscal, n 3, 1999, pp. $377-452$. 
NATIONAL INSTITUTE OF MENTAL HEALTH, Towards a Model for a Comprehensive Community-Based Mental Health System, Washington, DC, NIMH, 1987.

NEWMAN, G., "Cómo evaluar el estado mental" -versión de febrero de 2018-, Manual MSD. Versión para profesionales.

NOVELLA, E. J., "Los límites de la tecnocracia: la modernización autoritaria de la asistencia psiquiátrica en la España del segundo franquismo", Dynamis, Vol. 39, $\mathrm{n}^{\circ}$ 1, 2019, pp. 73-97. http://dx.doi.org/10.30827/dynamis.v39i1.8667

PÉREZ FERNÁNDEZ, F. y PEÑARANDA ORTEGA, M., "El debate en torno a los manicomios entre los siglos XIX y XX: el caso de Nellie Bly", Revista de la Asociación Española de Neuropsiquiatría. 2011, Vol. 37, no 131, ene./jun. 2017, pp. 95-112.

QUINTERO OLIVARES, G., Locos y culpables, Pamplona, Aranzadi, 1999.

REVELLES CARRASCO, M., "Personas reclusas con trastorno mental grave: el éxodo tras la reforma psiquiátrica en España”, Revista de Historia de las Prisiones, $\mathrm{n}^{\circ} 9$ (julio-diciembre 2019), pp. 111-134.

REVIRIEGO PICÓN, F., " "Derechos de los reclusos; el análisis desde la perspectiva de las personas con discapacidad", en CAMPOY CERVERA, I., Los derechos de los reclusos y la realidad de las cárceles españolas. Perspectivas sociales, políticas, jurídicas y filosóficas, colección "Debates del Instituto Bartolomé de las Casas", $n^{\circ}$ 27, Madrid, Dykinson, 2017, pp. 139-159.

ROLDÁN BARBERO, H., “¿Adónde van los enfermos mentales que cometen delitos?", Revista Electrónica de Estudios Penales y de la Seguridad, $\mathrm{n}^{\circ} 5$ (2019), pp. 1-21.

RODRÍGUEZ LAFORA, G.; PEREZ-VALDES, R. y BUSQUET, T.. "Los manicomios españoles", Revista 
de la Asociación Española de Neuropsiquiatría, Vol. 31, $\mathrm{n}^{\circ}$ 4, oct./dic. 2011, pp. 777-789.

RODRÍGUEZ NOGUERA, M.V, MOREIRA MARTÍNEZ, M. M., BUSTOS CARDONA, T. y SIMÓN LORDA, D., "PANAP (Patronato Nacional de Asistencia Psiquiátrica): un organismo público para la asistencia psiquiátrica durante la dictadura de Franco (1939-1975). El caso del Hospital Psiquiátrico de Tóen-Ourense-Galicia-España”, en PEREIRA, A. L. y RUI PITA, J. (eds.), V Jornadas Internacionais de História da Psiquiatría e Saúde Mental, Coimbra, Universidade de Coimbra, 2015, pp. 91-100.

RODRÍGUEZ YAGÜE, C., "El Derecho Penitenciario Humanitario", Anuario de Derecho Penal y Ciencias Penales, Vol. LXXII, 2019, pp. 439-482.

ROMERO ÁllareZ, J. J. y MOLINA MARTÍN, J. D., "Esquizofrenia y delincuencia: análisis de la jurisprudencia del Tribunal Supremo entre 2008 y 2018", Revista Internacional Jurídica y Empresarial, $\mathrm{n}^{\mathrm{o}} 2$ 2, 2019, pp. 81-126. 10.32466/eufv-r.i.j.e.2019.2.538.81-126

SANZ, J., GÓMEZ-PINTADO, P., RUIZ, A., POZUELO, F. y ARROYO, J. M., "Programa de Atención Integral al Enfermo mental en las prisiones españolas (PAIEM). Valoración tras cuatro años de funcionamiento", Revista Española de Sanidad Penitenciaria, $\mathrm{n}^{\mathrm{o}} 16,2014$, pp. 91-102.

SECRETARÍA GENERAL DE INSTITUCIONES PENITENCIARIAS, Hospitales Psiquiátricos dependientes de la Administración Penitenciaria. Propuesta de Acción, 2011.

SECRETARÍA GENERAL DE INSTITUCIONES PENITENCIARIAS, Informe General 2018, Madrid, Ministerio del Interior/Secretaría General Técnica, s/f.

SINGLETON, N., MELTZER, H., GATWARD, R. COID, J. y DEASY, D., Psychiatric morbidity among

Estudios Penales y Criminológicos hitps://doi.org/10.15304/epc.41.6718 -129- ol. XLI (2021). ISSN 1137-7550: 59-135 
prisoners in England and Wales, London, Stationery Office, 1998.

SUBDIRECCIÓN GENERAL DE SANIDAD PENITENCIARIA, "Estudio sobre Salud Mental en el Medio Penitenciario. Diciembre - 2006", en Estrategia Global de Actuación en Salud Mental, Ministerio del Interior, 2007.

TAMARIT SUMALLA, J. M., "Culpabilidad, maldad e imputabilidad: aportaciones de la dogmática penal a la cultura jurídica europea", Revista de Derecho Penal y

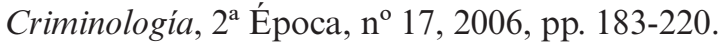

URRUELA MORA, A., Las medidas de seguridad y la reinserción social en la actualidad. Especial consideración de las consecuencias jurídico-penales aplicables a sujetos afectos de anomalía o alteración psíquica, Granada, Comares, 2009.

VICENS, E., TORT, V., DUEÑAS, R. M., MURO, A., PÉREZ-ARNAU, F., ARROYO J. M., ACÍN, E., DE VICENTE, A., GUERRERO, R., LLUCH, J., PLANELLA, R. y SARDA, P., "The prevalence of mental disorders in Spanish prisons", Criminal Behaviour and Mental Health, $\mathrm{n}^{\circ}$ 21, 2011, pp. 321-332.

VILLAREJO RAMOS, A., "El criterio de causalidad en la valoración de la imputabilidad de los trastornos de la personalidad", Cuadernos de Medicina Forense, $\mathrm{n}^{\circ} 33$, 2003, pp. 25-33.

ZABALA BAÑOS, C., Prevalencia de trastornos mentales en prisión: Análisis de la relación con delitos y reincidencia, Madrid, Ministerio del Interior/Secretaría General Técnica, 2017. 


\section{Anexo jurisprudencial}

\begin{tabular}{|c|c|c|}
\hline REF. ECLI & $\begin{array}{l}\text { ANOMALÍA O ALTERACIÓN } \\
\text { PSÍQUICA }\end{array}$ & CALIFICACIÓN \\
\hline ES:TS:2015:21 & TR. ESQUIZO-AFECTIVO & EX. INCOMPLETA \\
\hline ES:TS:2015:757A & $\begin{array}{l}\text { ESQUIZOFRENIA } \\
\text { PARANOIDE }\end{array}$ & INAPRECIABLE \\
\hline ES:TS:2015:1855A & ESQUIZOFRENIA & ATENUANTE \\
\hline ES:TS:2015:543 & TR. ADAPTATIVO & INAPRECIABLE \\
\hline ES:TS:2015:1303A & $\begin{array}{l}\text { ESQUIZOFRENIA } \\
\text { PARANOIDE }\end{array}$ & ATENUANTE \\
\hline ES:TS:2015:1708A & TR. PSICÓTICO & INAPRECIABLE \\
\hline ES:TS:2015:1071 & $\begin{array}{l}\text { ESQUIZOFRENIA } \\
\text { PARANOIDE }\end{array}$ & INAPRECIABLE \\
\hline ES:TS:2015:1257 & TR. DE LA PERSONALIDAD & EX. INCOMPLETA \\
\hline ES:TS:2015:1498 & PSICOSIS ANFETAMÍNICA & ATENUANTE \\
\hline ES:TS:2015:2719 & $\begin{array}{l}\text { BAJA INTELIGENCIA Y } \\
\text { DEPENDENCIA }\end{array}$ & INAPRECIABLE \\
\hline ES:TS:2015:4503A & $\begin{array}{l}\text { ESQUIZOFRENIA } \\
\text { PARANOIDE }\end{array}$ & EX. INCOMPLETA \\
\hline ES:TS:2015:4470A & $\begin{array}{l}\text { ESQUIZOFRENIA } \\
\text { PARANOIDE }\end{array}$ & EX. INCOMPLETA \\
\hline ES:TS:2015:3059 & RETRASO MENTAL & EX. INCOMPLETA \\
\hline ES:TS:2015:4920A & TR. PSICÓTICO & ATENUANTE \\
\hline ES:TS:2015:2961 & DEPRESIÓN & INAPRECIABLE \\
\hline ES:TS:2015:5941A & $\begin{array}{l}\text { ESQUIZOFRENIA } \\
\text { PARANOIDE }\end{array}$ & EX. INCOMPLETA \\
\hline ES:TS:2015:3249 & $\begin{array}{l}\text { BAJA CAPACIDAD } \\
\text { COGNITIVA }\end{array}$ & INAPRECIABLE \\
\hline ES:TS:2015:6615A & ESQUIZOFRENIA & ATENUANTE \\
\hline ES:TS:2015:3499 & ALCOHOLISMO & INAPRECIABLE \\
\hline ES:TS:2015:4295 & $\begin{array}{l}\text { RETRASO MENTAL Y } \\
\text { SOCIOPATÍA }\end{array}$ & INAPRECIABLE \\
\hline ES:TS:2015:4843 & TR. ANTISOCIAL & INAPRECIABLE \\
\hline ES:TS:2015:5423 & TR. DE IDEAS DELIRANTES & ATENUANTE \\
\hline ES:TS:2015:5266 & $\begin{array}{l}\text { ESQUIZOFRENIA } \\
\text { PARANOIDE }\end{array}$ & EX. COMPLETA \\
\hline ES:TS:2015:10868A & ESQUIZOFRENIA RESIDUAL & INAPRECIABLE \\
\hline
\end{tabular}




\begin{tabular}{|c|c|c|}
\hline REF. ECLI & $\begin{array}{l}\text { ANOMALÍA O ALTERACIÓN } \\
\text { PSÍQUICA }\end{array}$ & CALIFICACIÓN \\
\hline ES:TS:2016:277 & TR. PARANOIDE & ATENUANTE \\
\hline ES:TS:2016:1554A & TR. BIPOLAR & EX. INCOMPLETA \\
\hline ES:TS:2016:631 & RETRASO MENTAL & EX. INCOMPLETA \\
\hline ES:TS:2016:669 & CONSUMO DE DROGAS & INAPRECIABLE \\
\hline ES:TS:2016:2171A & CRISIS PSICÓTICA & EX. COMPLETA \\
\hline ES:TS:2016:1757A & ESQUIZOFRENIA RESIDUAL & ATENUANTE \\
\hline ES:TS:2016:826 & TR. DEPRESIVO Y PSICOSIS & INAPRECIABLE \\
\hline ES:TS:2016:923 & LUDOPATÍA & INAPRECIABLE \\
\hline ES:TS:2016:2632A & $\begin{array}{l}\text { ANSIEDAD Y PSICOSIS } \\
\text { PARANOIDE }\end{array}$ & ATENUANTE \\
\hline ES:TS:2016:4406A & CONSUMO DE DROGAS & INAPRECIABLE \\
\hline ES:TS:2016:4445A & $\begin{array}{l}\text { TR. PERSONALIDAD Y CI } \\
\text { LÍMITE }\end{array}$ & ATENUANTE \\
\hline ES:TS:2016:4974A & $\begin{array}{l}\text { ESQUIZOFRENIA PARA- } \\
\text { NOIDE }\end{array}$ & EX. INCOMPLETA \\
\hline ES:TS:2016:4708A & $\begin{array}{l}\text { ESQUIZOFRENIA PARANOI- } \\
\text { DE Y AMNESIA }\end{array}$ & ATENUANTE \\
\hline ES:TS:2016:2316 & DEMENCIA MIXTA & EX. COMPLETA \\
\hline ES:TS:2016:2558 & ONIOMANÍA & ATENUANTE \\
\hline ES:TS:2016:2717 & $\begin{array}{l}\text { RETRASO MENTAL Y TR. } \\
\text { ESQUIZOIDE }\end{array}$ & INAPRECIABLE \\
\hline ES:TS:2016:2944 & $\begin{array}{l}\text { ESQUIZOFRENIA } \\
\text { PARANOIDE CRÓNICA }\end{array}$ & ATENUANTE \\
\hline ES:TS:2016:3044 & $\begin{array}{c}\text { TR. DEPRESIVO Y } \\
\text { PERSONALIDAD LÍMITE }\end{array}$ & ATENUANTE \\
\hline ES:TS:2016:3925 & TOXICOMANÍA CRÓNICA & INAPRECIABLE \\
\hline ES:TS:2016:8076A & $\begin{array}{l}\text { ESQUIZOFRENIA } \\
\text { PARANOIDE }\end{array}$ & INAPRECIABLE \\
\hline ES:TS:2016:4205 & $\begin{array}{l}\text { ESQUIZOFRENIA } \\
\text { PARANOIDE }\end{array}$ & INAPRECIABLE \\
\hline ES:TS:2016:10499A & $\begin{array}{l}\text { ESQUIZOFRENIA CON } \\
\text { PSICOSIS AGUDA }\end{array}$ & EX. COMPLETA \\
\hline ES:TS:2016:4420 & $\begin{array}{l}\text { TR. ANSIEDAD Y OBSESIVO } \\
\text { COMPULSIVO }\end{array}$ & INAPRECIABLE \\
\hline ES:TS:2016:4629 & $\begin{array}{l}\text { PSICOSIS ESQUIZOFRÉNICA } \\
\text { PARANOIDE }\end{array}$ & EX. COMPLETA \\
\hline
\end{tabular}




\begin{tabular}{|c|c|c|}
\hline REF. ECLI & $\begin{array}{l}\text { ANOMALÍA O ALTERACIÓN } \\
\text { PSÍQUICA }\end{array}$ & CALIFICACIÓN \\
\hline ES:TS:2016:11684A & $\begin{array}{c}\text { ESQUIZOFRENIA } \\
\text { PARANOIDE Y OTROS }\end{array}$ & ATENUANTE \\
\hline ES:TS:2017:37 & LUDOPATÍA & INAPRECIABLE \\
\hline ES:TS:2017:88 & PEDOFILIA & INAPRECIABLE \\
\hline ES:TS:2017:440 & LUDOPATÍA & INAPRECIABLE \\
\hline ES:TS:2017:2874A & ESQUIZOFRENIA RESIDUAL & INAPRECIABLE \\
\hline ES:TS:2017:4080A & $\begin{array}{l}\text { ESQUIZOFRENIA } \\
\text { PARANOIDE }\end{array}$ & EX. COMPLETA \\
\hline ES:TS:2017:1176 & $\begin{array}{l}\text { TR. EMOCIONAL Y } \\
\text { ANTISOCIAL }\end{array}$ & EX. INCOMPLETA \\
\hline ES:TS:2017:1177 & $\begin{array}{l}\text { TR. PSICÓTICO CON } \\
\text { IDEACIÓN DELIRANTE }\end{array}$ & ATENUANTE \\
\hline ES:TS:2017:1594 & DISTIMIA Y PSICOTICISMO & INAPRECIABLE \\
\hline ES:TS:2017:4754A & $\begin{array}{c}\text { TR. PSICÓTICO Y } \\
\text { PERSONALIDAD LÍMITE }\end{array}$ & EX. INCOMPLETA \\
\hline ES:TS:2017:1851 & $\begin{array}{l}\text { SÍNDROME DELIRANTE } \\
\text { SENSITIVO }\end{array}$ & ATENUANTE \\
\hline ES:TS:2017:6798A & $\begin{array}{l}\text { ESQUIZOFRENIA } \\
\text { PARANOIDE Y OTROS }\end{array}$ & ATENUANTE \\
\hline ES:TS:2017:2105 & $\begin{array}{l}\text { TRASTORNO LÍMITE E } \\
\text { HISTRIÓNICO }\end{array}$ & INAPRECIABLE \\
\hline ES:TS:2017:2800 & PREVIO ICTUS CEREBRAL & INAPRECIABLE \\
\hline ES:TS:2017:2569 & $\begin{array}{l}\text { ESQUIZOFRENIA } \\
\text { PARANOIDE }\end{array}$ & INAPRECIABLE \\
\hline ES:TS:2017:3173 & ESQUIZOFRENIA AFECTIVA & EX. INCOMPLETA \\
\hline ES:TS:2017:2545 & $\begin{array}{c}\text { PERSONALIDAD } \\
\text { ESQUIZOIDE Y CI LÍMITE }\end{array}$ & INAPRECIABLE \\
\hline ES:TS:2017:2823 & ADICCIÓN AL ORDENADOR & INAPRECIABLE \\
\hline ES:TS:2017:8909A & $\begin{array}{l}\text { ESQUIZOFRENIA CON } \\
\text { APLANAMIENTO }\end{array}$ & INAPRECIABLE \\
\hline ES:TS:2017:3330 & $\begin{array}{l}\text { PERSONALIDAD } \\
\text { ESQUIZOIDE Y OTROS }\end{array}$ & INAPRECIABLE \\
\hline ES:TS:2017:3740 & $\begin{array}{c}\text { ESQUIZOFRENIA } \\
\text { PARANOIDE Y ADICCIÓN }\end{array}$ & ATENUANTE \\
\hline ES:TS:2017:3867 & ESQUIZOFRENIA Y OTROS & EX. COMPLETA \\
\hline ES:TS:2017:12620A & $\begin{array}{l}\text { ESQUIZOFRENIA } \\
\text { PARANOIDE Y OTROS }\end{array}$ & INAPRECIABLE \\
\hline
\end{tabular}




\begin{tabular}{|c|c|c|}
\hline REF. ECLI & $\begin{array}{l}\text { ANOMALÍA O ALTERACIÓN } \\
\text { PSÍQUICA }\end{array}$ & CALIFICACIÓN \\
\hline ES:TS:2017:13068A & $\begin{array}{l}\text { ESQUIZOFRENIA } \\
\text { PARANOIDE }\end{array}$ & EX. COMPLETA \\
\hline ES:TS:2018:3447A & $\begin{array}{l}\text { ESQUIZOFRENIA } \\
\text { PARANOIDE RESIDUAL }\end{array}$ & INAPRECIABLE \\
\hline ES:TS:2018:1729A & $\begin{array}{c}\text { ESQUIZOFRENIA } \\
\text { PARANOIDE Y OTROS }\end{array}$ & INAPRECIABLE \\
\hline ES:TS:2018:4253A & $\begin{array}{l}\text { ESQUIZOFRENIA } \\
\text { PARANOIDE }\end{array}$ & ATENUANTE \\
\hline ES:TS:2018:6810A & $\begin{array}{l}\text { TR. PSICÓTICO DE LARGA } \\
\text { EVOLUCIÓN }\end{array}$ & EX. INCOMPLETA \\
\hline ES:TS:2018:1632 & PARKINSON & INAPRECIABLE \\
\hline ES:TS:2018:2094 & $\begin{array}{l}\text { ESQUIZOFRENIA Y } \\
\text { ALCOHOLISMO }\end{array}$ & EX. INCOMPLETA \\
\hline ES:TS:2018:2553 & IDEACIÓN DELIRANTE & ATENUANTE \\
\hline ES:TS:2018:8549A & $\begin{array}{l}\text { TR. CRÓNICO ANSIEDAD Y } \\
\text { DEPRESIÓN }\end{array}$ & EX. INCOMPLETA \\
\hline ES:TS:2018:3291 & $\begin{array}{l}\text { ESQUIZOFRENIA } \\
\text { PARANOIDE }\end{array}$ & ATENUANTE \\
\hline ES:TS:2018:3518 & $\begin{array}{l}\text { TR. PARANOIDE, PSICOSIS, } \\
\text { DEPENDENCIA }\end{array}$ & EX. INCOMPLETA \\
\hline ES:TS:2018:3548 & PSICOPATÍA & INAPRECIABLE \\
\hline ES:TS:2018:3804 & $\begin{array}{l}\text { TR. ESQUIZO-AFECTIVO } \\
\text { DELIRANTE }\end{array}$ & EX. COMPLETA \\
\hline ES:TS:2018:3959 & $\begin{array}{l}\text { TR. ADAPTATIVO Y DE } \\
\text { PERSONALIDAD }\end{array}$ & ATENUANTE \\
\hline ES:TS:2018:4219 & $\begin{array}{c}\text { PERSONALIDAD } \\
\text { CELOTÍPICA Y OBSESIVA }\end{array}$ & ATENUANTE \\
\hline ES:TS:2019:82 & ADICCIÓN A VIDEOJUEGOS & INAPRECIABLE \\
\hline ES:TS:2019:39 & PARAFILIA & ATENUANTE \\
\hline ES:TS:2019:2895A & $\begin{array}{l}\text { INTELIGENCIA LÍMITE Y } \\
\text { OTROS }\end{array}$ & INAPRECIABLE \\
\hline ES:TS:2019:1356 & PEDOFILIA & EX. INCOMPLETA \\
\hline ES:TS:2019:8356A & ESQUIZOFRENIA & EX. INCOMPLETA \\
\hline ES:TS:2019:7610A & $\begin{array}{l}\text { INTELIGENCIA BAJA Y } \\
\text { ANALFABETISMO }\end{array}$ & INAPRECIABLE \\
\hline ES:TS:2019:2335 & $\begin{array}{l}\text { TR. MIXTO DE LA } \\
\text { PERSONALIDAD }\end{array}$ & INAPRECIABLE \\
\hline
\end{tabular}




\begin{tabular}{|lcr|}
\hline REF. ECLI & ANOMALÍA O ALTERACIÓN & CALIFICACIÓN \\
\hline PS:QUICA & PERSONALIDAD MIXTA & \\
ES:TS:2019:2313 & CLUSTER B.E.C. & INAPRECIABLE \\
& PEDOFILIA & INAPRECIABLE \\
ES:TS:2019:3314 & ESQUIZOFRENIA & \\
ES:TS:2019:13122A & PARANOIDE Y ADICCIÓN & INAPRECIABLE \\
& PEDOFILIA & ATENUANTE \\
ES:TS:2019:4251 & TR. SOMATOMORFO Y & \\
& RETRASO MENTAL & ATENUANTE \\
ES:TS:2020:289 & ESQUIZOFRENIA & \\
& PARANOIDE Y ADICCIÓN & EX. COMPLETA \\
ES:TS:2020:1541A & TR. DISTÍMICO E IDEAS & \\
ES:TS:2020:530 & DELIRANTES & EX. COMPLETA \\
& LUDOPATÍA & INAPRECIABLE \\
ES:TS:2020:814 & ANOMALÍA CEREBRAL Y R. & \\
& PSICOPÁTICOS & INAPRECIABLE \\
ES:TS:2020:1347 & ESQUIZOFRENIA & \\
& PARANOIDE & ATENUANTE \\
ES:TS:2020:2046 & PERSONALIDAD LÍMITE Y & ONAPRECIABLE \\
ES:TS:2020:5768A & ESQUIZOFRENIA & INAPRECIABLE \\
\hline
\end{tabular}

